\title{
The Chief Clinical Informatics Officer $(\mathrm{CClO})$
}

\section{AMIA Task Force Report on CCIO Knowledge, Education, and Skillset Requirements}

Joseph Kannry'; Patricia Sengstack²; Thankam Paul Thyvalikakath ${ }^{3,4}$; John Poikonen ${ }^{5}$; Blackford Middleton ${ }^{6}$; Thomas Payne ${ }^{7}$; Christoph $\mathrm{U}$ Lehmann ${ }^{8}$; on behalf of the AMIA Task Force Report on CCIO Skillset and Educational Requirements*

${ }^{1}$ Mount Sinai Health System, NY, NY;

${ }^{2}$ Bon Secours Health System, Marriottsville, MD;

${ }^{3}$ Indiana University School of Dentistry, Indianapolis, IN;

${ }^{4}$ Regenstrief Institute, Indianapolis, IN;

${ }^{5}$ University of Massachusetts, Lowell, MA;

${ }^{6}$ Harvard TJ Chan School of Public Health, Boston, MA;

${ }^{7}$ University of Washington, Seattle, WA;

${ }^{8}$ Vanderbilt University, Nashville, TN;

\section{Keywords}

Medical informatics/education, curriculum/standards, medical education, medical graduate, nursing education graduate, nursing education post graduate, pharmacy education graduate, dental education graduate, fellowships and scholarships/standards

\section{Summary}

Introduction: The emerging operational role of the "Chief Clinical Informatics Officer" (CCIO) remains heterogeneous with individuals deriving from a variety of clinical settings and backgrounds. The CCIO is defined in title, responsibility, and scope of practice by local organizations. The term encompasses the more commonly used Chief Medical Informatics Officer (CMIO) and Chief Nursing Informatics Officer (CNIO) as well as the rarely used Chief Pharmacy Informatics Officer (CPIO) and Chief Dental Informatics Officer (CDIO).

Background: The American Medical Informatics Association (AMIA) identified a need to better delineate the knowledge, education, skillsets, and operational scope of the CCIO in an attempt to address the challenges surrounding the professional development and the hiring processes of $\mathrm{CCIOs}$. Discussion: An AMIA task force developed knowledge, education, and operational skillset recommendations for $\mathrm{CCIO}$ focusing on the common core aspect and describing individual differences based on Clinical Informatics focus. The task force concluded that while the role of the CCIO currently is diverse, a growing body of Clinical Informatics and increasing certification efforts are resulting in increased homogeneity. The task force advised that 1.) To achieve a predictable and desirable skillset, the CCIO must complete clearly defined and specified Clinical Informatics education and training. 2.) Future education and training must reflect the changing body of knowledge and must be guided by changing day-to-day informatics challenges.

Conclusion: A better defined and specified education and skillset for all CCIO positions will motivate the $\mathrm{CCIO}$ workforce and empower them to perform the job of a 21st century $\mathrm{CCIO}$. Formally educated and trained $\mathrm{CCIO}$ s will provide a competitive advantage to their respective enterprise by fully utilizing the power of Informatics science.

\footnotetext{
* AMIA Task Force on CCIO Skillset and Educational Requirements included Joseph Kannry (Chair), Steven J. Davidson, Tonya Hongsermeier, Christoph U. Lehmann, Larry Ozeran, Thomas Payne, John Poikonen, Patricia P. Sengstack, Roy L. Simpson, Thankam Paul Thyvalikakath, Thomas Yackel, Barbara B. Frink Special acknowledgement: Kevin M. Fickenscher
} 


\section{Correspondence to:}

Joseph Kannry MD

Mount Sinai Health System

Icahn School of Medicine at Mount Sinai

Division of General Internal Medicine

Box 1087

1 Gustave L. Levy Place

NY, NY 10029

Email: joseph.kannry@mountsinai.org
Appl Clin Inform 2016; 7: 143-176

http://dx.doi.org/10.4338/ACl-2015-12-R-0174

received: December 7, 2015

accepted: December 11, 2015

published: March 16, 2016

Citation: Kannry J, Sengstack P, Thyvalikakath TP, Poikonen J, Middleton B, Payne T, Lehmann CU, on behalf of the AMIA Task Force Report on CCIO Skillset and Educational Requirements. The Chief Clinical Informatics Officer (CCIO):AMIA Task Force Report on CCIO Knowledge, Education, and Skillset Requirements. Appl Clin Inform 2016; 7: 143-176

http://dx.doi.org/10.4338/ACl-2015-12-R-0174 


\section{Introduction}

For the last 50 years, the initially gradual and now pervasive implementation and adoption of electronic health records created a demand for new health system clinical informatics roles, both tactical and strategic in nature, that support clinical practice and institutional missions in health systems.

Electronic health records (EHR) were introduced in the 1960s when academic centers developed the first systems under the leadership of physicians and early informaticians like Octo Barnett, Clem McDonald, Reed Gardner, Homer Warner, Bill Stead, Ed Hammond, and others [1, 2]. Along with the emergence of health information technology (HIT) and the evolution from rudimentary to vastly complex, sophisticated systems capable of transforming healthcare [3], a need arose for leaders and stewards, who can design, implement, manage, and leverage these systems. In the 1980s, the Chief Information Officer (CIO) began to fill this need. To date, the CIO is an accepted and required role in most health system organizations [4]. The Chief Clinical Informatics Officer (CCIO) was recently added to the healthcare leadership teams to compliment the CIO. While the CCIO term is still rarely used, the term encompasses the more commonly used Chief Medical Informatics Officer (CMIO) and Chief Nursing Informatics Officer (CNIO) as well as the seldom used Chief Pharmacy Informatics Officer (CPIO) and Chief Dental Informatics Officer (CDIO).The term Chief Health Informatics Officer (CHIO) is sometimes used synonymously with $\mathrm{CCIO}[5]$. CCIOs may also report to a CHIO for overall supervision[6].

To date, the CCIO role has not been well defined nor has the role been derived from a clear set of expectations, skillsets, or educational standards. Organizational position descriptions vary significantly and even its Wikipedia definition remains vague: "Typically the CMIO is a physician with some degree of formal health informatics training or a working equivalent thereof, ..."[7]. The American Medical Informatics Association (AMIA) recognizes the need for a shared understanding of the definition, educational background, optimal organizational context, required skillsets, and educational background of the CCIO role. This report aims to address this need.

Clinical Informatics has grown into a science of "analyzing, designing, developing, implementing, and evaluating information and communication systems that enhance individual and population health outcomes, improve patient care, and strengthen the clinician-patient relationship"[8]. The leaders of this science have evolved from early adopters and research pioneers to highly skilled experts in applied systems in common use, often tasked with change management activities such as stakeholder engagement, re-engineering, and transformation. Clinical informatics leaders harness the power of HIT systems to reduce medical errors, promote the practice of evidence-based medicine, improve quality and efficiency of medical care, and provide tools to make new discoveries that were impossible with paper records. Lessons learned from successes and failures - technical, sociotechnical, political, clinical, or financial - have helped to influence the practice of professionals in these roles.

With pervasive information technology affecting most patient care processes, health care organizations must pay attention to the knowledge, education, and skillset of CCIOs, who serve as vital links between $\mathrm{CIO}$ and the clinical communities. As knowledge of the field of Clinical Informatics grows[9], it is imperative that leaders possess informatics knowledge as well as the leadership skills to assume the role of change agent needed to successfully implement knowledge in clinical practice. Ineffective use of or ineffective CCIO leaders may compromise the transformation potential of clinical system implementations with negative effects on providers and patients. Thus, effectively hiring and leveraging the CCIO is an opportunity that today's healthcare delivery organizations cannot afford to squander.

The Chief Clinical Informatics Officer (CCIO) still is an emerging operational role in health systems, whose exact title, responsibilities, and scope of practice vary and remain defined in the context of the local organization. To date, CCIOs exist as a heterogeneous group with individuals deriving from a variety of clinical settings and backgrounds.

This paper uses the title "Chief Clinical Informatics Officer" to describe the person in charge of "Clinical Informatics". Ensuring that the health system understands and incorporates effectively essential clinical HIT requires the addition of the CCIO to the traditional CIO position. While CCIOs may originate from clinical disciplines including dentists, pharmacists, nurses, and physicians, historically and currently non-clinicians have very successfully executed this role. However, the CCIO 
position requires insight and experience in the health care setting. Some organizations have multiple CCIOs for multiple clinical informatics disciplines: "Chief Medical Information/Informatics Officer (CMIO)", "Chief Nursing Information/Informatics Officer (CNIO)", and less commonly "Chief Pharmacy Information/Informatics Officer (CPIO)" and "Chief Dental Information/Informatics Officer (CDIO)". The title implies the area of informatics that the CCIO leads and not the originating clinical specialty (or a clinical specialty at all) of the CCIO. These "Chiefs" are responsible for their informatics domain's interactions with the organization's information technology group as well as clinical knowledge management and inclusion of evidence based practices as it relates to clinical information systems. AMIA defines the term CCIO as a collective title and an umbrella for leadership positions that are clinical informatics discipline specific. That does not preclude an individual from holding a position responsible for more than one discipline.

AMIA acknowledges that much like the role of CCIO; the title is far from standardized and may vary from organization to organization. Titles such as "Director Clinical Information Technology" or "Clinical Information Management Director" and other similar titles reflect the knowledge or practice of the particular person, rather than their professional discipline, and their role may cover activities of multiple disciplines.

This white paper explores the current role of the CCIO and defines it further by clearly delineating each discipline's respective $\mathrm{CCIO}$ role and respective Clinical Informatics education and related skillsets in operational or executive leadership positions based on the current literature as well as reported experience from experts. Despite the paper's focus on the differences between the Chief Clinical Informatics Officers, there are more commonalities than differences.

\section{Background}

\subsection{Area of Rapidly Increasing Demand: 2009-Present}

The 2009 American Recovery and Reinvestment Act (ARRA) [10] included the Health Information Technology for Economic and Clinical Health Act (HITECH Act), which established requirements for certified electronic health record technology as well as criteria to which health-care providers and hospitals must adhere, and quality measures, on which they must report, to qualify as meaningful users of health information technology (HIT) and to benefit from incentive payments and avoid penalties.

Since the signing of the HITECH act, organizations began to focus on rapid implementation of clinical systems to help them achieve meaningful use (MU). As a result, a great demand for CCIOstyle professionals and informaticians developed. A large number of people from a variety of backgrounds and disciplines were hired to fill positions to meet the demand.

\subsection{Development of Educational Requirements}

Significant progress has been made defining the educational requirements for Clinical Informaticians in Medicine [11-13], Nursing [14-16], Pharmacy [17-19], and Dentistry [20, 21]. However, to date, the required education and skills for the Chief Clinical Informatics Officers have not been well delineated, thus complicating the professional development of those aspiring to these types of roles and the hiring processes for those seeking qualified informatics leaders. The current state of the CCIO roles may vary greatly in definition, requirements, and responsibility across institutions and care settings. This paper is not intended nor should it be used to be prescriptive or exclusionary, but to provide a framework of recommendation for the education, training, and selection of this work force to meet current and future demand.

\subsection{CCIO History}

The number of CCIOs has increased in recent years driven mainly by the significant growth in CMIO (Chief Medical Information Officer) positions [22]. Through financial incentives, MU increased EHR adoption with more clinicians interacting directly with clinical information systems. 
Subsequently, healthcare institutions increased efforts to address clinician reluctance and resistance in the adoption of clinical computing applications. A medical informatics leader, familiar with clinical workflow and the impact of EHRs on communication and workload, understands and effectively promotes the advantages of HIT systems to patients, clinicians, and organizations, and can be an important component in the implementation and maintenance of EHRs and other HIT tools [23-27]. Further, CCIOs have played a lead role in ensuring that technology supports the emerging and growing changes to healthcare payment models based on value and outcomes.

\subsubsection{CMIO}

Medical Informatics involvement in healthcare computing has a lengthy history that predates the CCIO. The early medical informatician role was investigator and system developer. In pioneering organizations medical informaticians or physicians often led teams or departments devoted to health information technology [28]. Others conducted externally-funded research on how computing systems might improve quality [29, 30], improve resource utilization[31], and aid decision-making [32].

The need for a CMIO or "Medical Information Officer" was first enunciated by Friedman, Slack, and colleagues in the late 1980's [33-36]. The first CMIOs were hired in the early 1990s, and by the middle of that decade the term CMIO was first formally defined by healthcare recruiters [37]. The 'I' in CMIO initially referred to "Information". In the beginning of the 21st century, the 'Information' was occasionally replaced with the word 'Informatics'. At the time of this paper, the term 'Information' is frequently replaced with the word "Informatics". From the 1970s to the 1990s, hospitals and large ambulatory care practices with computing systems integral to operations, had remarkable successes leveraging health IT [38-47]. The National Library of Medicine funded post-doctoral fellowships in many of these early adopter sites $[48,49]$. These fellowships focused on Clinical Informatics and added to the potential labor pool of CMIO's by providing formal Informatics training.

Initially, the CMIO was defined as a senior leader in health information technology [50-52] - frequently a physician. The number of CMIO positions grew slowly in the 1990s even though CMIOs were perceived as critical to the success of health care systems [23, 53, 54]. In 2006, 30\% of CIOs employed CMIOs [55]. MU significantly accelerated the engagement of CMIOs [22]. In 2011, 66\% of CIO's were supported by a CMIO [56] increasing to 75\% by 2012 [22]. The creation of CMIO.net (2011) and CMIO Magazine (2012) reflected increasing CMIO numbers and a burgeoning professional pool. A 2012 survey found that the vast majority of CMIOs had been in the current position for only 1-3 years. Only 4\% had been in the same position for 9+ years [57]. Accelerated by $\$ 29$ billion in incentives (as of August 2015) [58], two thirds of the CMIOs were hired in the wake of HITECH. Growth of the CMIO community is reflected in attendee numbers at vendor meetings', new organizations (like AMDIS) and publications targeting CMIOs like Applied Clinical Informatics (www.aci-journal.org), and the Board Certification in Clinical Informatics first administered by the American Board of Preventive Medicine in 2013.

When the role of CMIO emerged, initially the individuals filling these positions were diverse in their background, training, and skillset with a trend towards more homogeneity as time progresses. Today's CMIOs emerged from various backgrounds: Many had no formal informatics training. Some merged into this role from hospital leadership or committee such as Medical Records or Health Information Management committees. Others worked on clinical informatics research or operational pilot projects. Thus, the skillset, expertise, and competency of today's CMIO vary and so do the tasks the CMIO are capable of tackling. Only after the new profession has established itself, will standardization occur through standardized training requirements. For CMIOs, the first steps towards that standardization occurred when AMIA became the de facto home for Clinical Informatics professionals and developed an Applied Informatics track for its annual meetings in 2003 $[59,60]$, followed by the first board certification in Clinical Informaticians in 2013 and the establishment of the first ACGME accredited Clinical Informatics fellowships in 2014.

\subsubsection{CNIO}

The role of the Chief Nursing Informatics Officer (CNIO) emerged over the last decade with the realization that leadership is required to bridge the gap between clinical care and technology for the largest sector of healthcare workers - an estimated 3 million US nurses. 
Nursing informatics has a long history and traces its roots back to Florence Nightingale, who in the 1850's compiled and processed data to improve sanitation in military hospitals through nursing and medical protocols [61]. The ANA defines nursing informatics as: "the specialty that integrates nursing science with multiple information management and analytical sciences to identify, define, manage, and communicate data, information, knowledge, and wisdom in nursing practice. Nursing informatics supports nurses, consumers, patients, the interprofessional healthcare team, and other stakeholders in their decision-making in all roles and settings to achieve desired outcomes. This support is accomplished through the use of information structures, information processes, and information technology" [16].

Nursing informatics was officially recognized as a specialty with board certification in 1992 by the American Nursing Association (ANA) [16]. The ANA professional standards contain performance measures for nurses pursuing higher levels of accountability, responsibility, and leadership (like CNIOs) including expectations for teamwork, creation of a healthy work environment, clear vision and goals, coordination and execution of plans, participation in professional organizations, commitment, and key leadership roles [16].

In 2012, the American Organization of Nurse Executives (AONE) - when describing the role of the "Nursing Informatics Executive" leader - captured the essence of a CNIO as a C-Suite position influencing not only the technology but also the entire enterprise's delivery of patient care [62, 63].

\subsubsection{CPIO}

In the 1877, pharmacist Isaac Smith, established the first health information exchange with a telephone connection between his drugstore in Hartford, CT and 21 local physicians [64]. Ambulatory pharmacists used patient profiles and inventory management systems in the 1960s [65]. Pharmacy information systems were among the first systems installed in healthcare organizations. Medication charge capture in hospitals was an early priority and required computerization. The first drug interaction checking in an automated system was described in 1970 [66].

Despite the early involvement, only a handful of Chief Pharmacy Informatics Officers (CPIO) work in health systems today [67]. However, mid-level pharmacy informatics roles are commonplace.

\subsubsection{CDIO}

Unlike medicine, where specialists outnumber primary care providers [68, 69], dentistry is mainly a primary care discipline with 166,000 dentists in US of whom 70 percent are solo practitioners. Dentists usually work in isolation except for those in community clinics and hospitals. In developed countries, the expense of dental treatment causes major health disparities due to access to care [70].

The chief dental informatics officer's (CDIO) position and role remain poorly defined. The designation CDIO is rarely used except in the Veteran Affairs (VA) health administration, which employs dental informaticians in leadership positions. Despite the transition from paper to dental electronic health records, CDIO positions are uncommon in dental academia, HMOs, or in community clinics. Dentists with administrative positions such as Associate Dean, Department Chair, or Director are often required to lead the implementation and management of dental EHRs assisted by IT managers. However, only a handful of these dentists have informatics expertise through work experience or formal informatics education and training.

In many dental practices, the dentist/owner leads the EHR implementation assisted by IT consultants or dental EHR vendors. Little consideration for the impact on workflow or decision-making during patient care have resulted in poor usability of dental EHRs, increased work load, and reduced time with patients [71-73]. The National Institute of Dental and Craniofacial Research established the first dental practice-based research networks (DPBRN) in 2005 to support big data analyses from dental EHRs to increase efficiency, lower research cost, and permit longitudinal studies not feasible with traditional methods [74]. 


\subsection{The CCIO Role}

CCIOs must closely follow the emerging and growing changes to healthcare payment models based on value and outcomes. Ensuring that informatics supports these models is imperative to their success as care delivery changes.

\subsubsection{CMIO}

The Department of Veterans Affairs - an early adopter of HIT - created new positions (Associate Chief of Staff for Clinical Information Management, Medical Director of IT Services, Director of Medical Informatics, Director of Clinical Information Technology, Medical Director of Information Technology Service, etc.) which antedate the CMIO. First the VA and later other institutions hired people in these roles realizing that informaticians leading the implementation and maintenance of clinical computing systems added value.

Many early titles can be mapped to the later CMIO title. Over time, the term Chief Medical Information Officer was used for the individual providing clinical informatics leadership - regardless of role variations due to local requirements, expectations, protocols, and customs. Early on, CMIOs were valued by executive leadership for familiarity and credibility with physician colleagues, which allowed lobbying and recruiting of clinicians to become adopters. Their understanding of clinical environments, workflows, and healthcare rules were seen as helpful for effective implementation and workflow design. First-hand system use during clinical practice allowed for identification and remediation of flaws resulting in improved end user satisfaction, increased productivity and safety, and potentially a return on the investment. The price for these benefits required a significant reduction in clinical (patient care) duties [75]. However, devoting salary support to CMIOs is becoming increasingly perceived as a good investment because of the high-cost strategic and critical nature of EHRs within health systems. Sharing of the CMIO among hospitals, particularly within a large health system, is increasing. Not surprisingly national recruiting for CMIOs appears to be accelerating.

The organizational reporting structure surrounding the CMIO is varied. The AMDIS-Gartner survey that found that three models are most widespread [76, 77]. Most commonly, the CMIO reports to the Chief Information Officer. Alternatively, the CMIO may report to the CEO or CMO/ Chief of Staff. Models vary with dotted reporting lines by which the CMIO may report to multiple organizational leaders [76].

\subsubsection{CNIO}

The CNIO role is more robustly defined than the CMIO role due to the longer existence of formalized nursing informatics leadership and certification. A CNIO is instrumental in creating the vision, influencing health IT decisions, and providing leadership to successfully meet the challenges of a continually evolving technologic environment [78].

In 2012, the American Organization of Nurse Executives (AONE) [62, 63] recognized that the CNIO is a C-Suite position not only influencing nursing technology, but the entire enterprise's delivery of patient care including quality, safety, and financial outcomes. The various titles for nurses in CNIO roles included Director of Nursing Informatics, VP Nursing Informatics, and Chief Clinical Informatics Officer. Historically CNIOs have advanced degrees supported by AONE's proposal that "Nursing Informatics Executive leadership roles are best served by individuals with a Master's degree" and recognition of a trend towards doctoral degrees [62, 63].

In 2011, the Robert Wood Johnson Foundation and the Institute of Medicine (IOM) [79] asserted that healthcare reform cannot take place without strong leadership from within the ranks of the largest component of healthcare's workforce - nurses. The report in conjunction with two other papers $[80,81]$ proposed key recommendations for nurse leaders:

- Knowledge of the care delivery system, teamwork, effective collaboration (intra- and inter-disciplinary), principles of ethical care, patient advocacy, theories of innovation, and the foundation for quality and safety improvement.

- Partnering with nurse executives to lead technology changes that advance health and the delivery of healthcare.

- Supporting the development of informatics departments.

- Fostering the evolution of the Chief Nursing Informatics Officer role 
CNIOs are critical in achieving the American Nurse Credentialing Center's Magnet Recognition, obtaining incentive payments from Meaningful use, implementing new payment models such as Accountable Care Organizations, creating Patient Centered Medical Homes, and promoting Value Based Purchasing. Nursing informatics leaders establish the strategies and plans, define and measure HIT performance, and provide technology and informatics solutions that result in improved clinical and financial outcomes for patients and organizations. As a result, the CNIO must remain up to date and be fluent in technology developments as well as federal and local initiatives $[78,82,83]$.

A 2011 survey on CNIO demand, governance structures, and reporting relationships in the healthcare IT environment [84] revealed that organizations recognized the need for strong nursing leadership in the implementation of electronic health records. Parallel to the CMIO, new federal mandates requiring nursing information technology, elevated the importance of the CNIO. Barriers to the emergence of this role included [84] a lack of a clear role definition resulting in organizational variation of CNIO role requirements as well as lack of perceived necessity by an unaware or uninformed senior leadership.

The reported primary skillset for the CNIO role includes nursing professional, educator, informatics educator (advanced), strategist, collaborator, manager, and leader. Institutional governance depends on collaboration and strategic partnerships thus making a matrix-type relationship with the CNO fundamental for the nurse informatics executive. Reporting structures for CNIOs varied with the majority reporting to the Chief Nursing Officer (CNO - 28\%) followed by the Chief Information Officer (CIO - 25\%) [84] with an agreement that a dotted line should exist to the CNO. As organizations implement more clinical systems in response to federal HIT regulations, the CNIO role will continue to mature and further self-define[84].

\subsubsection{CPIO}

Pharmacy Informatics provides safe and effective medication selection and prescribing, verification, dispensing, administration, and monitoring. Informatics knowledge, education, and skillsets relate to the clinical and the drug distribution role of the profession. Technologies have been instrumental in re-engineering the delivery of medication therapy and the medication use process including medication decision support and cost containment managed care programs [85].

While pharmacy adopted computing systems and informatics principles early, to date it lags behind medicine and nursing in the formalization and delineation of the knowledge, education, and skillsets required for pharmacy informaticians let alone CPIOs. Pharmacy informatics has yet to define a body of knowledge to support a certification or advanced recognition, which may be partly responsible for the paucity of CPIOs. Even with the increase in CMIO and CNIO positions, most health systems do not have an equivalent role for pharmacy informatics. Nevertheless, employment opportunities for pharmacists with informatics skills are plentiful ( $>$ Figure 1$)$.

To date the CPIO role remains poorly defined. The knowledge, education, and skills set of a CPIO is focused around the medication use process. CPIOs may provide value through leadership for of medication-use systems [86] extending into pharmacy operations, medication safety, quality improvement, pharmaceutical waste, medication preparation, and medication administration. Specific tasks may include vendor selection and contracting, vulnerability assessment, prevention strategy, and decision support. Pharmacy Informatician involvement in medication decision support $[87,88]$ has increased due to MU incentivized EHR implementations and required integration between pharmacy information systems and CPOE[26].

Pharmacy Informatics positions in health systems have titles such as Informatics Pharmacy Specialists, Informatics Pharmacists, or Pharmacy Informaticians. Larger health systems typically employ several pharmacists dedicated to CPOE, medication decision support, health information exchange, automated drug dispensing, administration, robotics, and medication monitoring technologies.

In 2007, the American Society of Health System Pharmacists (ASHP) created a member section for Pharmacy Informatics and Technology and defined pharmacy informatics "as the use and integration of data, information, knowledge, technology, and automation in the medication use process for the purpose of improving health outcomes [85]". Also in 2007, the Accreditation Council for Pharmacy Education Standards and Guidelines [18] mandated that "[...] pharmacists must be edu- 
cated to deliver patient-centered care as members of an interprofessional team, emphasizing evidence-based practice, quality improvement approaches, and informatics." Additional requirements included demonstrated expertise in informatics by pharmacy graduates. Updated guidance in 2011 [89] defined expertise to include basic terminology, rationale for systematic processing of data, information, and knowledge, data use in quality improvement initiatives, and benefits and constraints of information and communication technology. Further educational guidance is anticipated from AMIA's Advanced Interprofessional Informatics Certification (AIIC) [90].

Formal pharmacy-specific informatics training opportunities are rare but exist in form of Masters in Healthcare Informatics programs open to pharmacists and a few post-graduate informatics specific pharmacy residency programs. Pharmacy informatics roles are frequently vendor specific. Despite these definitions, requirements, and training opportunities, specialty practice designation or board certification status has yet to occur.

The reporting structure for pharmacy informaticians is through the pharmacy department to the Chief Pharmacy Officer or Director of Pharmacy reflective of the history of pharmacy information systems, which historically were implemented as ancillary systems owned by the pharmacy. This independence from institutional IT departments has all but vanished due to MU. As EHRs with CPOE were being adopted in hospitals, pharmacy systems became an integral part of HIT. Today the few individuals in large health systems, who occupy the CPIO roles, have reporting relationships to the $\mathrm{CIO}$, and/or the CMIO. With increasing attention in pharmacy to patient safety, reporting relationships to Quality Officers emerged as well.

In the past eight years, job trends for pharmacy informatics has kept pace with other informatics specialists in nursing and medicine, which will likely lead to more CPIOs. ( Figure 1)

\subsubsection{CDIO}

Dentistry has a shorter record of accomplishment than medicine and nursing with clinical information systems and the evolution of Dental Informatics is tied to the slow development of robust dental information systems. Dentistry adopted dental EHRs mainly to automate administrative functions and enhance practice efficiency [21, 71, 91]. Only recently, did the use of dental EHRs for clinical purposes increase dramatically and dental EHRs evolved to include documentation, digital radiographs, patient education, and prevention of oral disease $[21,71]$.

Almost all dental schools now use dental EHRs and half manage complete patient information electronically $[21,92]$. Currently, $70 \%$ of US dental practices manage some information electronically and $15 \%$ manage complete patient information electronically $[68,93]$ - a significant increase from 2006 (37\% and 2\% respectively) [69, 94]. This increase is attributable to Meaningful Use, which incentivized dentists for using EHRs from 2011 onwards [95]. However, the number of CDIOs did not increase correspondingly.

Dental informatics has grown rapidly during the last decade and its workforce consists of approximately 20 informaticians, who developed expertise both through work and experience and formal informatics education and training [96].

Much like Pharmacy Informatics, Dental Informatics is shaped by its relationship with other health care disciplines. In contrast to Medicine, Nursing, and even Pharmacy, Dentistry as a discipline emerged and developed autonomously [97] due to the prevalence of tooth decay and lack of interest by physicians in the mechanical and surgical management of tooth diseases. Dentistry waits for disease occurrence to then surgically manage it $[98,99]$; however, research on the etiology, prevalence, and preventive management of oral diseases and the recognition of the strong association of systemic diseases/conditions with oral health is now resulting in increased integration of dental with overall health care. Digitized dental patient data create opportunities to aggregate, dissect, and analyze data in novel ways including the study of patient populations. Limitations of reusing dental data for research remain, including poor data quality, lack of standards and interoperability of dental EHRs.

Dental informatics is critical to

1. move from a surgical model to a risk prevention model;

2. reduce risk factors common to chronic and oral diseases;

3. reuse dental EHR data to improve the quality of care and finally,

4. establish practice-based research. 
Dental informatics faces two key challenges: (1) establishing the value of and defining the responsibilities of CDIO in an Enterprise and (2) filling CDIO positions with trained and experienced informaticians.

\section{Knowledge, Education/Training, and Skillset}

While acknowledging that CCIOs currently have very diverse education and training and bring different knowledge and skills to their role, it is AMIA's position that standardization and redefinition of the position and its baseline knowledge, training, and skillset are required. In the hands of unskilled or careless leaders, health IT can fall short of its potential and may cause harm [100-104]. Implementation of HIT is complex [105] and difficult. To assure patient safety and provide return on investment for health information technology, AMIA supports standardization of training and a minimum set of qualifications for new CCIOs. The Nursing Informatics Certification, the Clinical Informatics sub-specialty board, and the ACGME accredited training programs aide in the standardization as will the Advanced Interprofessional Informatics Certification (AIIC) initiative and efforts to establish accreditation of medical informatics programs (CAHIIM).

To date CCIOs are predominantly clinicians, who have developed into informatics leaders. AMIA in an effort to assure standardization and to support the role of non-clinicians as CCIOs is developing a multidisciplinary certification process. The AIIC initiative - prioritized by the AMIA Board for 2015 - embarked upon the creation of a professionally robust clinical informatics examination [90]. The examination is to be parallel in content and rigor to the Subspecialty Certification in Clinical Informatics by the American Board of Preventive Medicine and will focus on certifying the common, advanced "core" informatics competencies (apart from any discipline-specific competencies) that would be relevant and available to all professions, for which informatics is a significant area of competency. The interdisciplinary AIIC Advisory Work Group will explore the core content and program training requirements for such a certification in consultation with AMIA's Academic Forum and will facilitate a pathway to develop and deliver the AIIC examination effectively and efficiently.

\subsection{Knowledge}

Among the basic requirements for the CCIO is an understanding of the science of informatics, the healthcare domain, clinical care processes, socio-technical challenges of care, communication, and clinical workflow. Without these basic requirements, the CCIO is unable to successfully communicate with customers, the clinicians, and to understand the impact and effects of health information technology on the care processes.

The need to understand clinical practice is stressed by the usual progression to CCIO. The role requires a clinician to first train and become proficient in a clinical specialty - which requires embedding the clinician into care processes and developing a deep understanding of the clinical realm and the users of health information technology. Subsequently, CCIOs are predominantly clinicians, who have developed into informatics leaders. Additionally, AMIA supports the role of non-clinicians as CMIOs through the multidisciplinary AIIC certification process.

For CCIOs, the core knowledge of Clinical Informatics lies at the intersection of knowledge on the health care system, clinical care, and information and communication technology. While distinctions between the different CCIOs exist, the core content of the specialty can be divided into Fundamentals including Clinical Informatics and the Health Care System, and Clinical Decision Making and Clinical Care Process Improvement, which includes Clinical Decision Support, Evidence Based Patient Care, Clinical Workflow Analysis, Process Redesign, and Quality Improvement, Health Information Systems, which covers Information Technology Systems, Human Factors Engineering, Health Information Systems and Applications, Clinical Data Standards, and Information System Lifecycle, Leading and Managing Change, which covers Leadership Models, Processes, and Practices, Effective Interdisciplinary Teams, Effective Communications, Project Management, Strategic and Financial Planning for Clinical Information Systems, and Change Management [12]. 
Advancing to a CCIO role requires leadership knowledge. For example, AONE requires that Nursing Informatics leaders have the vision, knowledge, and skills to leverage technology integration for clinicians to improve patient outcomes and for the C-suite to better position their organizations $[62,63]$. The needs of his/her organization require the CCIO to have other knowledge and skills beyond those required for any certification. Day-to-day practical knowledge, interpersonal skills, leadership, persistence, work ethic, and other skills not as easily attained as board certification will contribute to career success.

As health care delivery begins to move away from the acute care setting to outpatient arenas and the patient's home, CCIOs must possess knowledge of new and evolving technologies and determine strategies for incorporation into organizational strategic plans. New technologies include smart phones with apps, social media, and patient portals for enhanced patient engagement and data collection, telehealth technology to assist patients in remote settings, incorporation of genomics into the medical record, and improvements in data and predictive analytics providing better information for decision making.

The knowledge required to be a successful CCIO is and will be constantly changing. While today knowledge of MU and ICD-10 are important, other topics will take their place soon. It is AMIA's strong belief, that this constant change of required knowledge, changing regulations, novel technology, and new software solutions demands a dedication and commitment to lifelong learning by CCIOs. AMIA is committed to provide resources and materials to support ongoing learning by CCIOs through its conferences, workshops, and educational materials such as publications, webinars, podcasts, and videos.

\subsubsection{CMIO}

AMIA developed a de facto standard for the knowledge required for the sub-specialty of Clinical Informatics (applicable to CMIOs). The Gardner paper [12] describes the knowledge that an expert in Clinical Informatics must have and the Safran et. al. paper [13] describes the fellowship training requirements for such an expert. The American Board of Preventive Medicine and the American Board of Pathology have adopted this standard in the development of the examination and the eligibility criteria for those applying to take the Clinical Informatics board exam. Board certification may be the beginning for a career as a CMIO in the future.

\subsubsection{CNIO}

Knowledge and skills of a successful CNIO have previously been defined by ANA and ANCC [15]. The ANA concepts for informatics practice represent required knowledge and performance standards including measurement criteria for behaviors and activities, for which the informatics nurse should develop and maintain competency [16]. Examples of the categories include: Assessment, Problem and Issues Identification, Outcomes Identification, Planning, Education, Collaboration, Research, and Leadership. Additionally, the ANCC defined an extensive catalogue of nursing informatics knowledge required to pass the nursing informatics certification examination. ANCC concepts are synergistic with ANA's knowledge areas, and together they comprise the foundational informatics knowledge for leaders who aspire to a CNIO role [15]. Universities utilize these core concepts in nursing informatics curricula as they train a new workforce.

\subsubsection{CPIO}

Pharmacy informatics knowledge is both part of the broader field of clinical informatics and specific to pharmacy related topics such as the use of HIT in drug automation and delivery.

In 2010, a set of informatics competencies [19] was defined based on the Institute of Medicine's (IOM) inclusion of informatics as a core component for all health professionals' education [106]. Fox et al. [18] described pharmacy informatics-related education, knowledge, and skills for all pharmacy students. He broke down the specifics of the knowledge, education, and skills into: the medication use process of prescribing, pharmacist's review, compounding and dispensing, medication administration, and monitoring of ongoing mediation therapies. Fox further promoted pharmacy student acquisition of technology and informatics principles by participation in didactic course work, skills laboratory, observation rotation, and HIT vendor review. 
The Accreditation Council for Pharmacy Education (ACPE) emphasized informatics in the "Doctor of Pharmacy" curriculum including basic terminology knowledge (data, information, knowledge, hardware, software, networks, information systems, information systems management), understanding of systematic processing of data, information, and knowledge in healthcare, use of data in continuous quality improvement initiatives, and understanding of benefits and constraints of information and communication technology in health care.

Tribble et al [107] proposed a minimum knowledge and skillsets needed for pharmacy informatics professionals for a CPIO role. Some of knowledge required is obtainable through practical experience; other knowledge requires formal graduate level informatics training ( Table 1).

\subsubsection{CDIO}

Unlike the fields of medicine and nursing, dentistry does not yet have a well-defined description of the knowledge required for a dental informatician or a CDIO. Dentistry has been slow to develop and define informatics competencies for pre-doctoral students and dental informaticians although the need was outlined as early as 1992 [20]. Zimmerman et al defined proficiencies in informatics skills required of dental students and promoted development of dental informatics knowledge and competencies similar to nursing informatics by the American Dental Educators' Association. A dentist should (a) demonstrate a working knowledge of the technology and the basic principles of practice management that are used in computerized dental office information systems, (b) be capable of a request for proposal for a computerized practice management system, evaluate and rate vendor responses, (c) understand the strengths and weaknesses of the coding schemes presently used in dentistry, such as ADA procedure codes, ICD-9 diagnostic codes, MeSH terms, (d) understand the impact and relevance of large patient information databases that can be used to address issues of quality assurance, mercury levels in patients, the etiology of periodontal disease and other practicebased research studies, and anticipate the future uses of technology in the dental practice, such as automated periodontal probing, computer assisted design of dental restorations, computerized digital radiography and imaging, and computer assisted decision-making.

Unfortunately, twenty years later, dentistry is yet to formally create a consensus document on core competencies for dental informatics and the CDIO. Much like pharmacy, further educational guidance may be provided by AMIA's Advanced Interprofessional Informatics Certification (AIIC) [90].

The few schools offering a dental informatics program defined limited competencies for graduate dental informatics degrees: the ability to develop a vision and plan for organizational IT infrastructure, skills to hire and supervise IT personnel, competency in planning and leading the implementation of dental EHR systems, and the ability to establish an IT infrastructure for research, educational, and administrative purposes. Dental informatics students are required to take biomedical informatics courses, and additional requirements include foundational knowledge in medical informatics, statistics, and research.

In 2013, nationwide approximately 20 dental informaticians were engaged in improving care processes through effective use of information technology [96]. This accrual of professional expertise provides an opportunity for AMIA to work with major dental organizations to develop competency and knowledge requirements that set the direction for curriculum changes, faculty development, and continuing education for dental providers, researchers, educators, and dental informatics leaders.

\section{Education/Training}

Traditional health care training includes lectures, reading, work in a laboratory, then once graduated, supervised clinical responsibility leading to licensure and the ability to practice within the health care community. CCIO training in some cases has followed this path.

Informatics training must provide trainees with core competencies in Patient Care, Medical Knowledge, Practice-based learning and Improvement, Interpersonal and Communication Skills, Professionalism, and Systems based Practice. Trainees learn to leverage informatics tools to improve care planning, management, coordination, and follow-up, advance diagnosis, protect patient privacy 
and confidentiality. While some trainees may not be involved in direct patient care, they will understand and leverage the informatics tools to improve health promotion, disease prevention, diagnosis, care, and treatment of individuals and their families [13]. Trainees are to demonstrate an understanding of clinical utilization and the financial impact of clinical informatics. A special focus for Informatics trainee education is interdisciplinary work and the need for multi-cultural fluency. Informatics trainees must learn their role in the detection and disclosure of medical errors as part of their professionalism training. System based practice is a natural strong point of healthcare informatics, and the education must focus on evaluating, implementing, and improving systems. Often, trainees must document scholarly and research activity in this field including publications.

\subsection{CMIO}

Fellowships funded by the National Library of Medicine initially provided trainees with the opportunity of responsibility for overseeing clinical computing implementation and operations. With the rapid growth in clinical informatics, formal training opportunities have been overtaken by demand. Distance learning such as AMIA 10x10, ONC Regional Extension Centers, vendor- or organizationally-sponsored meetings, and other venues have provided some - albeit limited - training opportunities.

With Clinical Informatics Board Certification, a more formal structure to fellowships is arising in future ACGME accredited fellowships [13]. However, the majority of training until now has been undirected. Most CMIOs to date received their training "on the job", which is reflected in the practice path available until 2017 to gain board certification in Clinical Informatics.

Limited formal training in the past forced those tasked with informatics responsibility to learn through a variety of modalities. There is growing consensus that more formalized training is desirable going forward. Just as clinicians gain experience and skill after their clinical training through pattern recognition and exposure to clinical cases, formalized training will only provide the basis of the CMIO education and learning while "doing" will remain an integral part of the role.

AMIA strongly endorses the sub-board specialization of informaticians as a way for CMIOs to demonstrate dedication to the field, commitment to the specialty, and a mark of quality. Board certification in Clinical Informatics is not mandatory for a successful and effective CMIO, but it is likely that in the future more organizations will demand board certification as a role requirement.

Beginning in 2018 the sub-board specialization of Clinical Informatics will require the clinician to complete an Accreditation Council for Graduate Medical Education (ACGME) accredited fellowship. Education of Clinical Informatics fellows is designed to allow fellows to gain the skills needed to perform among others the role of CMIO.

ACGME accredited fellowships must comply with a number of requirements $[12,108]$. Besides demonstrating commitment to clinical informatics, research, and education, the program must provide a dedicated, qualified, experienced, and medically licensed program director. The program director must be committed to at least $20 \%$ effort and be board certified in informatics. While many requirements for the training of Clinical Informatics fellows mirror other fellowships, additional requirements exists such as the need for the training organization to have a robust clinical information system.

One critical aspect to fellowship education is the concept of continuity. Clinical Informatics fellows will have a continuity experience by being embedded for the duration of their fellowship in an interdisciplinary team that tackles a significant informatics challenge. This continuity requirement will provide "experiences in leadership, team management, and system life-cycles, and will provide better understanding of clinical information system projects in an organizational context."

\subsection{CNIO}

The training and education required to serve as CNIO is not taught at the baccalaureate level, nor is it typically acquired on the job alone. Many baccalaureate-nursing programs now offer an introductory informatics class that lacks the depth required for any leadership role.

CNIO positions now typically require graduate education in informatics with a leadership focus at both the masters and doctoral levels. At the master's level, students acquire the language and foun- 
dational concepts as delineated in ANA's Nursing Informatics Scope \& Standards of Practice[16]. Informatics nurses with a master's degree serve as clinical analysts, system configuration specialists, IT training educators, system testers, web designers, system implementation specialists, consultants, performance improvement specialists, security and privacy specialists - working with organizations throughout the system development lifecycle.

The doctoral level prepares for leadership roles within a single hospital and throughout larger systems. Preparation includes the development and evaluation of programs that benefit patient populations; lobbying at the local, state, and national levels; honing research and evaluation skills; assessment of organizational micro and macro systems; and understanding of the business and finances of healthcare.

It is the recommendation of the nursing community and task force that a CNIO hold a doctorate degree in order to serve as a partner and equal to others at the corporate table. Additionally, nurses serving in CNIO roles should also have a current board certification by the ANCC in nursing informatics.

\subsection{CPIO}

Recently, pharmacy leaders identified the need for an Information Technology leadership role called Medication-use Systems and Technology Pharmacist (MST) [86]. This role's focus on distribution technology may be the reason why the word "informatics" was omitted from the title. The MST position has the potential to evolve into a CPIO role with many reports in an integrated delivery network. The MST Pharmacist requires residency training of 1 or 2 years including training beyond the pharmacy informatics residency outlined above. The MST education includes experiences in broad operational oversight within a pharmacy department. MST pharmacist contributes to the medication safety and quality improvement aspects of the pharmacy department including oversight of technicians, sterile compounding, and pharmaceutical waste processes. The Chief Pharmacy Informatics Officer's role is a more senior role than the MST position. A CPIO would be expected to have the MST skills in addition to the general leadership skills.

\subsubsection{Pharmacy Residencies}

Only six $(0.4 \%)$ of the almost 1,500 pharmacy residency programs are informatics specialty programs. These six programs have challenging learning objectives inclusive of informatics principles [109]. Pharmacy informatics specialists

(a) improve patient outcomes through the application of pharmacy informatics principles, standards, and best practices,

(b) foster effective decision support for interdisciplinary health care teams,

(c) ensure accuracy of documentation and communication of medication orders using standard messaging vehicles, standard vocabularies, and clinically validated data,

(d) promote the safe and effective utilization of technology and pharmacy automation systems,

(e) execute project life cycles for pharmacy information technology or automation initiatives,

(f) function as a leader in pharmacy informatics,

(g) conduct pharmacy informatics research,

(h) demonstrate advanced skills in a specific technology or automation, and

(i) demonstrate skills required to function in an academic setting including research and education skills.

The CPIO will require advanced specialized residency and a Master's Degree in Informatics. The medication use process (including medication safety, administration, and surveillance) will be a key focus for the CPIO to establish leadership.

\subsection{CDIO}

In 1996, the NLM and the National Institute of Dental and Craniofacial Research (NIDCR) jointly funded three Dental Informatics (DI) training programs at Harvard, Temple (in collaboration with the University of Pittsburgh), and Columbia University. Programs admitted two pre-/postdoctoral 
trainees annually and granted Masters or Doctoral degrees. Harvard (2004) and Columbia (2008) discontinued their programs, primarily due to difficulty in recruiting and retaining trainees despite free tuition, a stipend, and health insurance. Temple University transferred its program to the University of Pittsburgh in 2001, where it has continued uninterrupted. A few individuals completed a traditional biomedical informatics program (not dental specific) and then pursued a career in dental informatics.

In 2012, the NLM/NIDCR awarded training grants to two more institutions: Oregon Health and Science University (OHSU) and the University of Wisconsin, Madison in collaboration with the Marshfield Clinic Biomedical Informatics Research Center. They also increased trainee positions to 3 pre-/postdoctoral fellows per year until 2017.

The existing dental informatics (DI) training programs focus on producing academicians resulting in two-thirds of the graduates accepting positions in academic or research organizations. However, the programs may prepare trainees for operational positions as well. Trainees are required to take courses in biomedical informatics and additional courses in dental informatics, which educate trainees on the nature of dental clinical workflows and practices, the unique needs of dental clinical systems, data representation, and the application of informatics research methods in designing and evaluating dental informatics interventions. Trainees learn to conduct needs analysis, evaluate, and select appropriate clinical systems, and assess system performance to improve clinical efficiency in dentistry. Thus, graduates are prepared to face the challenges and work processes unique for dentistry ( Table 1).

The research/academic focus of these programs, their length, and difficulty may have contributed to the recruitment problem for trainees. Licensed dentists and dental hygienists tend to focus on a subset of practical skills like knowledge to implement informatics systems and track data to assess clinical care processes and patient outcomes.

With the increasing adoption of dental EHRs due to the Meaningful Use incentive program [95, 110], there is a need for trained informatics expertise to facilitate implementation of certified EHRs. To address the acute need, the University of Pittsburgh's Center for Dental Informatics created an online course in 2013 "Introduction to Health Information Technology in Dentistry". After completion of the course, participants are able to

(a) understand how HIT can support the activities and processes of clinical dental care,

(b) select and evaluate HIT applications, and

(c) plan, administer, and manage HIT implementations.

The course covers transition from a paper-based to an EHR office, evaluation, decisions on the implementation approach, and identifying unintended adverse consequences. It also discusses applying administrative safeguards and risk analysis to comply with the HIPAA rules for privacy, security, and confidentiality. While online courses provide an overview of health information technology in dentistry, they are insufficient to provide the training and education required to serve the CDIO role.

\section{Skillset}

At present, much of the practice of health care informatics centers on the implementation, integration, and operation of commercial EHRs, other commercially purchased health information technology products, and the infrastructure that supports them. It is common for a CCIO to develop familiarity with a particular vendor product including its weaknesses and strengths and the best ways to leverage it. However, an understanding of universal clinical informatics and clinical decision support principles, such as Bates et al. "Ten Commandments for Effective Clinical Decision Support) [111] is critical to support the flexibility required by a CCIO to adapt to new technology, new vendors, and their products over the course of the CCIO's tenure.

The list of required skills for CCIOs is long. Some of them can be taught, many can be taught only partially, and others are inherent to an individual. Considering that one of the CCIO's most important roles is to engage end users as well as management, communication skills, interpersonal abil- 
ities, and the ability to influence others are critical. Balancing the "Cheerleader in Chief" role with advocacy for clinicians and patients is an essential characteristic of the CCIO position.

In 2011, the Deputy National Coordinator for Programs and Policy at the Office of the National Coordinator for Health IT defined the skills of the CNIO [82] that apply to all four CCIOs. A CCIO must be able to

(a) guide an electronic health record (EHR) system selection process,

(b) define an HIT governance process,

(c) engage senior executives in EHR culture and practice changes,

(d) advise on implementation methodology (big bang vs. incrementally phased) and on the sequencing for EHR modules,

(e) identify value proposition and key performance indicators for HIT implementations,

(f) provide oversight of system design and implementation,

(g) create implementation and key performance indicator score cards,

(h) determine an enhancement request system and a corresponding prioritization process,

(i) staff ongoing process improvement initiatives,

(j) educate on health technology and the interplay with people and process changes, develop strong relationships with key stakeholders in the organization including the other CCIOs.

Table 1 lays out knowledge, training, and the resulting skillset for all four CCIO types. The skills required by a CCIO, can be divided into three large categories that not only overlap but are integral to each other.

\subsection{Analytic, technical, and statistical skills}

A CCIO must have the ability to search and appraise the clinical informatics and medical literature critically to stay abreast of current developments, and more importantly avoid problems, failures, and pitfalls already reported by others. Similarly, a CCIO must be able to interpret clinical evidence and be able to translate the information into health IT applications for example through clinical decision support.

Fundamental programming, database design, and user interface design skills are needed to understand technical challenges such as network latency, evaluate issues such as help desk problems, communicate effectively with CIO, clinical and technical staff and developers, and guide in the selection of the appropriate tools for tasks.

Since the delivery of clinical informatics to the point of care involves use of electronic systems, interest in and facility with technology are obvious attributes of the CCIO.

\subsection{Management Skills}

A large aspect of the work of a CCIO is to oversee projects of varying size. Managerial skills required include budgeting, supervising interdisciplinary teams, as well as planning, reasoning, and prioritization skills. A CCIO must have superior analytical skills of workflow and user needs. Skills in devising and implementing applications and measuring their impact are important as well as change management skills. A CCIO must be familiar with state and federal laws and must be comfortable applying them to the IT products and the workflow in the organization.

Project managers are commonly involved in large initiatives. CCIOs benefit from understanding the project management process, but may not need to be skilled in managing projects themselves.

By virtue of serving as the Chief Clinical Information Officer, CCIOs should be leaders. Their ability to help the organization come to consensus or proceed with necessary work without it, and to assist clinicians with the process of change, all benefit from being a skilled leader. It is critical that the CCIO develop strong relationships with the $\mathrm{CMO}, \mathrm{CNO}, \mathrm{CIO}$, and other informatics leaders in the organization. 


\subsection{Interpersonal and Communication skills}

Some of the most important aspects of the CCIO skillsets are communication and interpersonal skills. Without them, any CCIO is likely to fail in the job. Educating users, engaging them, managing the institutional culture including the safety culture, and navigating the governance successfully are essential skills. Networking, negotiation, and an understanding of incentives for individuals and groups of providers as well as the ability to communicate effectively both up to management and across the users and developers are required to succeed. In academic settings, it is critical that the $\mathrm{CCIO}$ is recognized as a peer by researchers and educators and is perceived as understanding their language.

\subsection{CMIO}

The skillset expected from a CMIO can be derived from the required knowledge base and specified educational and training pathways. $>$ Table 1 maps the knowledge base required to present day pathways for education and training. Until 2017, there will be multiple ways including a Clinical Informatics fellowship, to become Board Eligible for the Subspecialty of Clinical Informatics. As of 2018, there will be only one path to Board eligibility: an ACGME accredited fellowship. Options such as Masters and PhDs will still exist, will enhance the existing knowledge and education, and will gain their own certification with AMIA's AIIC initiative. The education and training of CMIOs should lead to an expected measurable skillset.

\subsection{CNIO}

Factors of the CNIO's organization, including its culture, financial situation, care delivery model, and implementation state will determine the necessary skills. A 2011 survey of 377 CNIOs and other nursing informatics leaders identified the CNIO's skillset to be very congruent with other CCIO skills [84]. CNIOs must

(a) utilize the knowledge and skills of clinical practice,

(b) implement evidence based information systems,

(c) educate nurses and others on clinical technology,

(d) manage change, transform nursing practice through information technology, and measure outcomes,

(e) meet nursing informatics goals through negotiation, partnerships, empowerment, staff involvement, and motivation,

(f) manage partnerships in organization and vendor community,

(g) utilize effective management and leadership skills,

(h) translate public policy initiatives into practice and care delivery,

(i) and articulate the organization's vision and strategy for clinical transformation.

Dr. Stephanie Poe, CNIO at Johns Hopkins University, described the CNIO skill components to include

(a) transformational leadership,

(b) structural empowerment,

(c) exemplary professional practice,

(d) new knowledge, innovations, and improvements,

(e) and improving empirical outcomes [78].

An expected CNIO skillset can be derived from a required knowledge base and specified educational and training pathways. In $>$ Table 1 , the concepts from previously discussed professional Nursing organizations (ANA, ANCC, and AONE) and Nursing Informatics leaders have been combined to represent the knowledge, education, and skills required for those practicing at the CNIO level.

Our future CNIO's must possess a strong foundation of informatics knowledge as evidenced by the completion of graduate education and board certification. In addition, the ability to consult, 
educate, advise and guide an organization strategically through their informatics journey is a skill essential to the ultimate outcome of success - improved patient care. The range of skills needed for a CNIO will continually change from the core set of skills based on an organization's internal and external forces in play. The key skill is to be flexible, innovative, and ready to address any number of current and emerging informatics related issues - seeing each one as an opportunity for improvement.

\subsection{CPIO}

Trimble et al. also delineated skillsets essential for the pharmacy informatics professional. Change management, analytical, communication, and risk management skills are important for a pharmacist but essential for a pharmacy informatician. Project management and acquisition skillsets are only required for informaticians.

An expected CPIO skillset can be derived from a required knowledge base and specified educational and training pathways. > Table 1 maps the knowledge based in part derived from Tribble et. al. [107] to present day pathways for education and training. The education and training of CPIOs should lead to an expected and measurable skillset. Table 1 also maps CNIO education and training to the expected skillset, thus providing a list of skills any formally trained CPIO should have.

The specific title, CPIO has not become commonplace, but in the future, the need for more specialized expertise plus the development of a pharmacy informatics certification and potentially board exam will improve recognition of the CPIO. Like medicine and nursing, the pharmacy profession must elevate the stature and principles of pharmacy informatics as a recognized clinical specialty.

\subsection{CDIO}

As a reflection of the state of both knowledge and education/training, the skillsets for the CDIO still have yet to be defined. Despite a heightened priority for technology to improve dental education, clinical processes, and patient outcomes, there is limited understanding on the skillsets needed to lead the implementation and maintenance of dental EHRs. A review of literature revealed few publications that attempted to define the skillsets of CDIO. Schleyer at al [21] describe the CDIO position with the following skillsets: A CDIO must be able to

(a) provide a strategic vision to establish or improve the organizational IT infrastructure,

(b) act as a mediator/arbitrator between dental providers and IT staff to implement informatics interventions,

(c) negotiate and manage partnerships at all levels of the organization and with the vendor community to achieve dental informatics goals,

(d) identify organizational IT needs and hiring IT and informatics personnel with appropriate skillsets,

(e) plan, implement, maintain dental EHR systems and assess the impact on clinical and patient outcomes,

(f) lead the day-to-day operations affecting clinical workflow and care delivery,

(g) establish IT infrastructure to facilitate research, educational, and administrative computing,

(h) and be familiar with relevant state and federal policies especially related to patient privacy, confidentiality and security and able to translate it into practice.

An expected CDIO skillset can be derived from a required knowledge base and specified educational and training pathways. Table 1 maps the knowledge based to present day pathways for education and training. The education and training of CDIOs should lead to an expected and measurable skillset. $>$ Table 1 also maps CDIO education and training to the expected skillset, thus providing a list of skills any trained and board certified CDIO should have.

Lack of a consensus on knowledge, education, and skills for dental informaticians or CDIO makes it difficult to assess the ability of existing dental informatics training programs to fill operational positions. Like the medical subspecialty of clinical informatics, dental informatics may need both academic and operational fellowships. To move dental informatics forward, the scope of dental 
informatics profession and education must be defined formally - drawing from the work done by nursing and medical colleagues.

\section{Discussion}

AMIA's report introduces and defines the term Chief Clinical Informatics Officer (CCIO) as a role that encompasses many informatics disciplines including medical, nursing, pharmacy, and dental informatics. Organizations may employ CCIOs in one or multiple clinical disciplines. There is a shared need across CCIOs for structured, extensive, inter-and multispecialty focused Clinical Informatics education (used broadly to encompass all the activities of education from coursework to degrees to training), which leads to a defined skillset. AMIA acknowledges that while both experience and education must be present for the CCIO to be successful, experience alone is not sufficient for long-term success in a CCIO position.

The specifications and requirements for Clinical Informatics education are presently more clearly defined for physicians and nurses. For physicians, they take the form of the Core Content specified by Gardner et al [12] and used by the Clinical Informatics Subspecialty Board and the ACGME accredited training programs in Clinical Informatics [108]. For nurses, this education is defined by the Board Certification supported by ANA as well as graduate informatics education at the Masters and Doctoral levels. The level of specificity is less in both the graduate education and training for pharmacists and dentists as these two disciplines are earlier in the evolutionary process.

The skillsets that emerge from this formal education and training are of vital importance to the healthcare enterprise and likely will gain importance in the future. Ample evidence supports that formal education/training and the resulting skillset will improve care delivery. Two recent examples of this were the value of knowledge of taxonomies and ontologies in support of the conversion to ICD-10, and the incorporation of SNOMED into EHRs in Meaningful Use Stage 2.

It is the experience of task force members that employers and recruiters still lack understanding of the value of a Clinical Informatics education and the resulting skillsets. Recruiters in private conversation stated that they are rarely asked by their clients to screen candidates for the education and skillsets. This report seeks to educate potential employers and recruiters.

This report looks at today's CCIO roles across disciplines: CMIO, CNIO, CPIO, and CDIO. The task force's conclusions on the CCIO role are:

\subsection{To achieve a predictable and desirable skillset, the CCIO must com- plete clearly defined and specified Clinical Informatics education and training.}

The definition of Clinical Informatics by Gardner et. al. [12] clearly and broadly defines a discipline grounded in science applicable to all four disciplines. Informatics requires formal education and training much in the way a healthcare provider requires formal education and training before practicing. The body of knowledge covered by formal informatics and training for Clinical Informatics particularly in Medicine and Nursing ( $>$ Table 1) are well defined. Formalized education and skillsets resulting in certification are becoming critical to all senior roles in Clinical Informatics (i.e., CCIOs). The complexity of implementations and optimizations required for Clinical Information Systems demands such education and training.

The skillsets listed in $>$ Table 1 are the result of a defined and specified education and training. These skills are essential for CCIOs to perform as highly functional individuals. The various paths to such an education in the different specialties were outlined. The skillsets also require experience to be fully honed. Organizations must understand that patience is required to allow the CCIO to grow in his/her skills.

Clinical Informatics specialization helped to further define education and training requirements for the CMIO. Nursing informatics educational and training requirements lead to a very clearly defined and expected skillset for a CNIO. Even though skillsets for CPIOs and CDIOs are less well defined, this manuscript has provided the beginnings of a more detailed description. 
While the knowledge, education, and skillsets have been defined, it is the opinion of this task force that employers and recruiters have not universally recognized this knowledge, education, and skillset(s).

\subsection{The $\mathrm{CCIO}$ role evolved in two parallel but separate tracks resulting in poorly defined educational needs and skillsets}

In the past thirty years, Clinical Informatics evolved in two parallel tracks (especially in medical informatics). For lack of defined terms, we label them Experience and Academic Track.

In the Academic Track, clinical informaticians were formally trained and may have had some experience. Those in the Academic Track worked in academic centers that provided IT service roles in their institutions but prized innovation and new discovery.

In the Experience Track, clinical informaticians had no formal education and learned on the job. They often had a predisposition to HIT and their vast majority of learning occurred through experience. Research to explore scientific inquiry was an interesting luxury but the mission was to make sure HIT was implemented, maintained, and "kept on running". Service was highly prized.

There was overlap between the two tracks for Experience Track individuals, who pursued advanced education in the form of business degrees or HIT certification/degrees.

Meaningful Use disrupted the status quo through accelerated use of EHRs and caused the burgeoning discovery that experience alone is insufficient to both provide service and comply with the increasingly more challenging mandates of MU. Both education and experience are needed for leadership roles in Clinical Informatics. Nursing Informatics recognized this as early as 1992 [16]. The introduction of Clinical Informatics as a new sub-specialty board [12] and the development of ACGME accredited training programs [13] will aide in the standardization of the education as will the Advanced Interprofessional Informatics Certification (AIIC) initiative and its efforts to establish accreditation of medical informatics programs (CAHIIM).

\subsection{Varying definitions of Clinical Informatics resulted in diverse CCIO roles}

In the past, Experience and Academic Track led to two very different definitions of Informatics and quite different expectations. Recruiters and employers frequently note that there is no clear definition of the education, and skillset required for these positions. A recent survey of CMIOs demonstrated a great variation and diversity of responsibilities and reporting structures [112].

Informaticians are frequently disappointed to find that their formal education and skillset are not considered important criteria for job placement. As long as the needed education and skillsets are ill-defined or not recognized as requirements for the position by recruiters and decision makers, the $\mathrm{CCIO}$ role will continue to be diverse in role, responsibility, and reporting structure.

\subsection{Across the Four Clinical Informatics Disciplines there is a great deal in common}

All CCIO types require very similar and overlapping education. See $>$ Table 1 . Mapping IT plans, implementing and evaluating systems, managing user expectations and needs, and maintain systems to assure best possible service are themes that are across medical, nursing, pharmacy, and dental informatics. With the exception of the domain specific knowledge, the knowledge and skillset required for a successful CCIO are very congruent. As a result, it is feasible and desirable to combine some aspects of the education for future CCIOs to include all disciplines. Combined training will reduce costs, improve the quality of education, and will allow an early development of appreciation of the CCIOs in other domains. 


\subsection{Education and Skillset delineation are at different stages of devel- opment}

Of the four disciplines included in the CCIO, nursing informatics has worked on the formalization of education and skillsets the longest, dating back 20 years to the work of the ANA to create board certification [16]. As a result, nursing informatics has the most consistency and agreement and the most detailed specification of its CCIO role. Yet despite this lead, CCIO positions for nursing informatics (i.e., CNIOs) still have significant variability in responsibilities and reporting structures. The results of a survey in August 2011 found that senior leadership is still struggling to understand this role and in some cases is not even sure of its value [84]. The existence of well-defined training, board exams, and degrees does not guarantee that the position becomes mainstreamed.

AMIA enabled Medicine to come to a consensus and develop a board subspecialty certification in the subspecialty of Clinical Informatics. The first board examinations in Clinical Informatics were given in October 2013, the first applications for ACGME accredited fellowships in Clinical Informatics were approved in 2014.

Pharmacy and Dentistry Informatics are at much earlier stages of development. Dental and Pharmacy Informatics have to further define both knowledge and educational/training requirements along with resulting skillsets. This task force hopes that twenty-five years after Zimmerman's report [20] dentistry will finally see an initiative (perhaps supported by AMIA) to conclude this work. The work of AMIA's Advanced Interprofessional Informatics Certification (AIIC) may provide further guidance [90].

Until the education requirements are clearly defined, Dental and Pharmacy CCIOs will struggle to clearly define their Informatics leadership positions. Resultantly CMIOs and CNIOs will have limited access to their pharmacy and dental peers.

\subsection{Future education must be guided by praxis reflecting the changing body of knowledge and practice}

Clinical Informatics education and training programs require frequent revisions to their body of knowledge as new discoveries, innovations, and reports from the field develop. For trained Informaticians this means a commitment to life-long learning in the form of continuing education and maintenance of certification. Informatics by its nature is centered on rapidly changing technology and innovation that creates novel ways of conducting clinical care. For organizations training Informaticians this will require frequent reassessments and modifications to the curricula as would be true of any knowledge-based discipline.

The AIIC initiative - prioritized by the AMIA Board for 2015 - embarked upon the creation of a professionally robust clinical informatics examination [90]. The examination is to be parallel in content and rigor to the Subspecialty Certification in Clinical Informatics by the American Board of Preventive Medicine and will focus on certifying the common, advanced "core" informatics competencies (apart from any discipline-specific competencies) that would be relevant and available to all professions, for which informatics is a significant area of competency. The interdisciplinary AIIC Advisory Work Group will explore the core content and program training requirements for such a certification in consultation with AMIA's Academic Forum and will facilitate a pathway to develop and deliver the AIIC examination effectively and efficiently.

\subsection{Core content and training requirements must be disseminated to decision makers}

Reports such as this are only as valuable as the extent of their dissemination to decision makers, AND leaders, and THEIR subsequent adoption. A successful dissemination of this report will result in enhanced job descriptions for CCIO roles across the four disciplines. Recruiters and hiring executives will have a better understanding of what to look for in a future CCIO. 
The task force fell short of recommending that every CCIO complete Informatics certification. Within the next decade, there will be a sufficient number of board certified and trained graduates to predict that CCIOs, who are not certified, will slowly be phased out.

Most importantly given the current state of the Chief Clinical Informatics Officer roles, which may vary greatly, this report is not intended nor should it be used to be prescriptive or exclusionary, but to provide a recommendation to recruiters and decisions makers regarding the education, training, and selection of this work force to meet current and future demand.

\section{Conclusion}

Across all four disciplines Clinical Informatics education, training, and skillsets are specified and are particularly well defined in Medicine and Nursing. This task force recommends that a defined and specified education and skillset be required for all CCIO positions. The discipline specific and common requirements for Medical [12, 13], Nursing [16, 62, 79, 80], Pharmacy [17-19, 85] and Dental $[20,21]$ Informaticians will result in a dynamic motivated workforce of skilled people able and empowered to perform the job of a 21st century CCIO. We anticipate that these formally educated and trained CCIOs will provide a competitive advantage to their respective enterprise by fully utilizing the power of Informatics science.

\section{Clinical Relevance Statement}

To date, the required education and skills for these Chief Clinical Informatics Officers have not been well delineated, thus complicating the professional development of those aspiring to these types of roles and the hiring processes for those seeking qualified informatics leaders. Formally educated and trained CCIOs will provide a competitive advantage to their respective enterprise by fully utilizing the power of Informatics science.

\section{Human Subjects Protections}

The white paper was not a study and as such involved no human and/or animal subjects.

\section{Conflict of Interest:}

The authors declare that they have no conflicts of interest in regards to the work.

\section{Acknowledgements}

The task force would like to thank AMIA's Board of Directors for the excellent feedback and suggestions on the draft manuscript and Dr. Cindy Gadd for her description of the AIIC. 


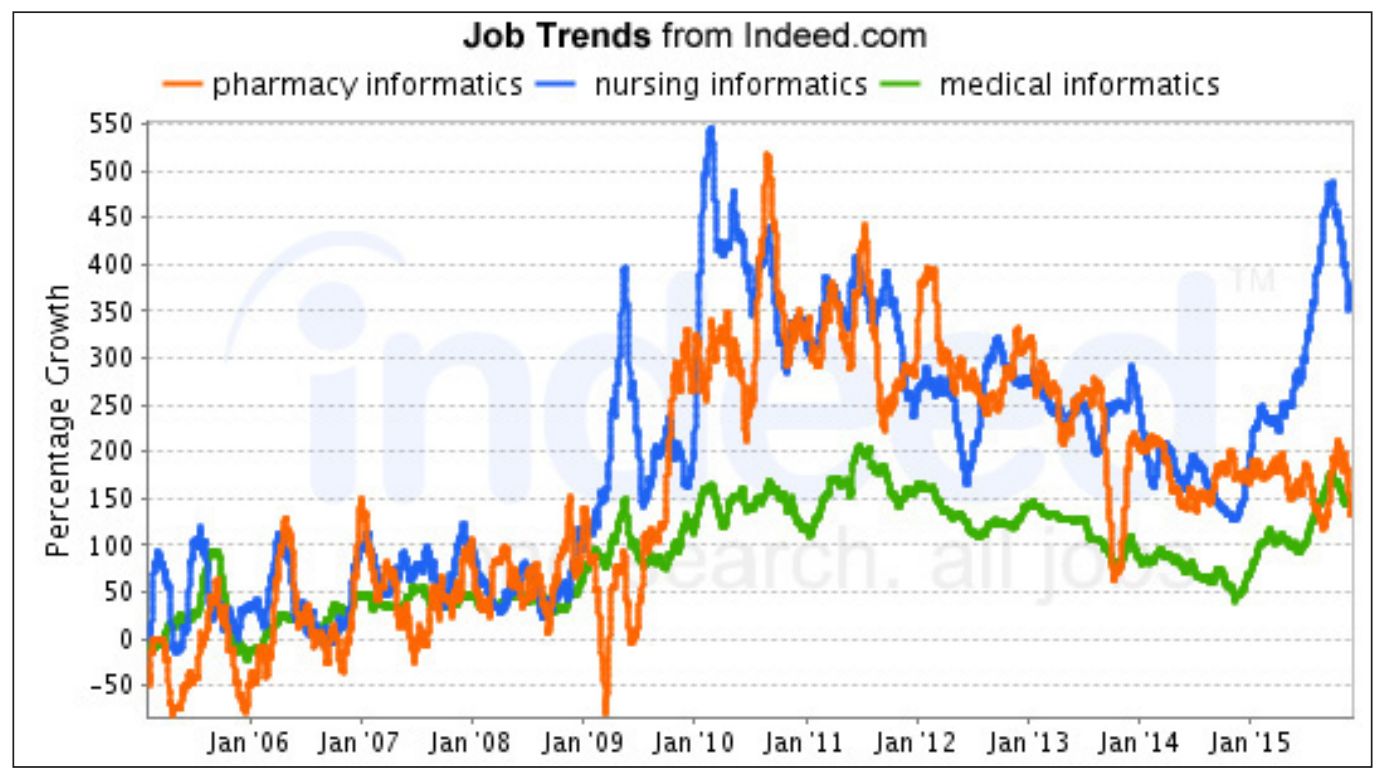

Fig. 1 Job trends for pharmacy informatics (with friendly permission by: Indeed, Inc., Austin, TX, Source: http://www.indeed.com/jobtrends?q=pharmacy+informatics $\% 2 C+$ nursing+informatics $\% 2 C+$ medical+in formatics\&l=\&relative $=1$ ) 


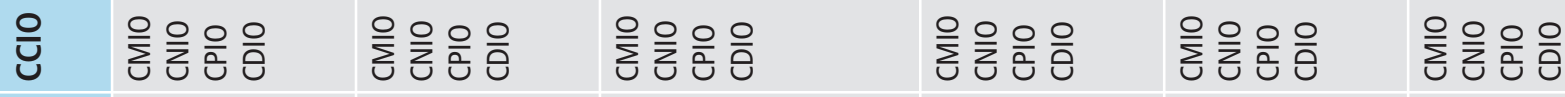
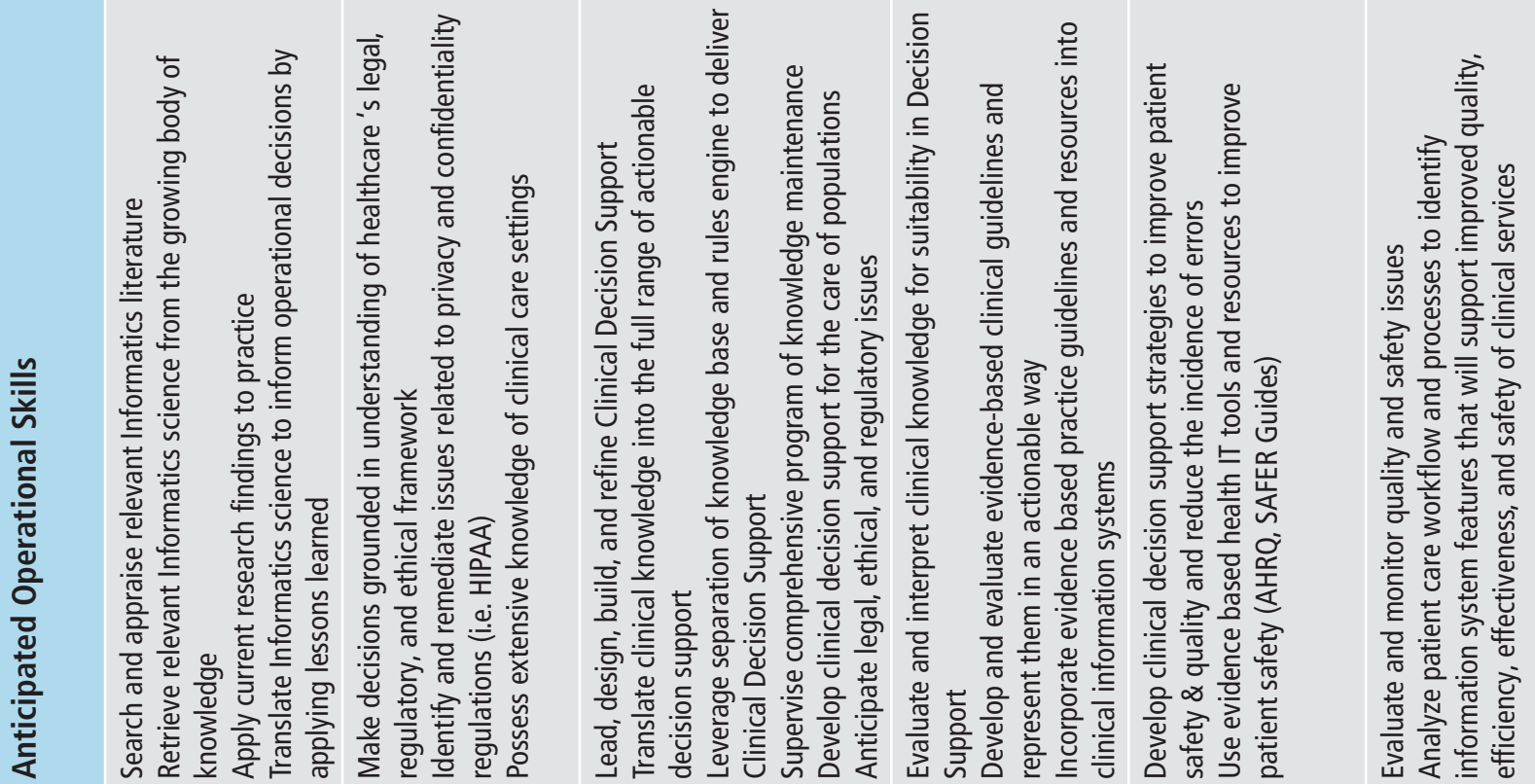

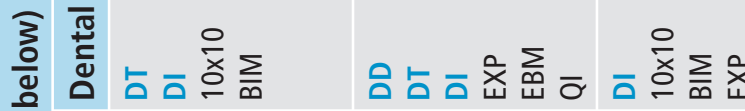

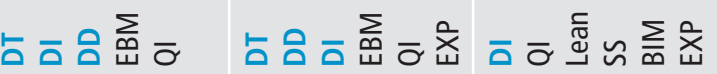

$-\propto \frac{0}{x} \Sigma$

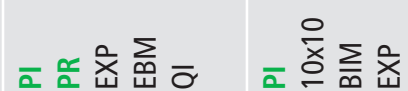

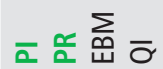

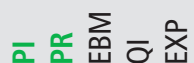

$\bar{\Sigma} \overline{\stackrel{\complement}{\varpi}} \backsim$ 玄

욜

$\frac{0}{8}$

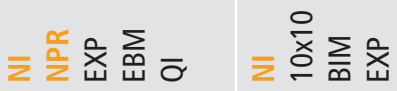

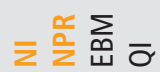

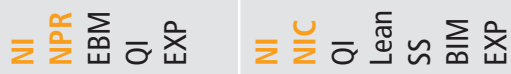

言

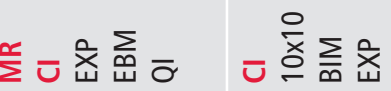

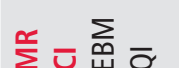

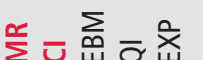

ஏ
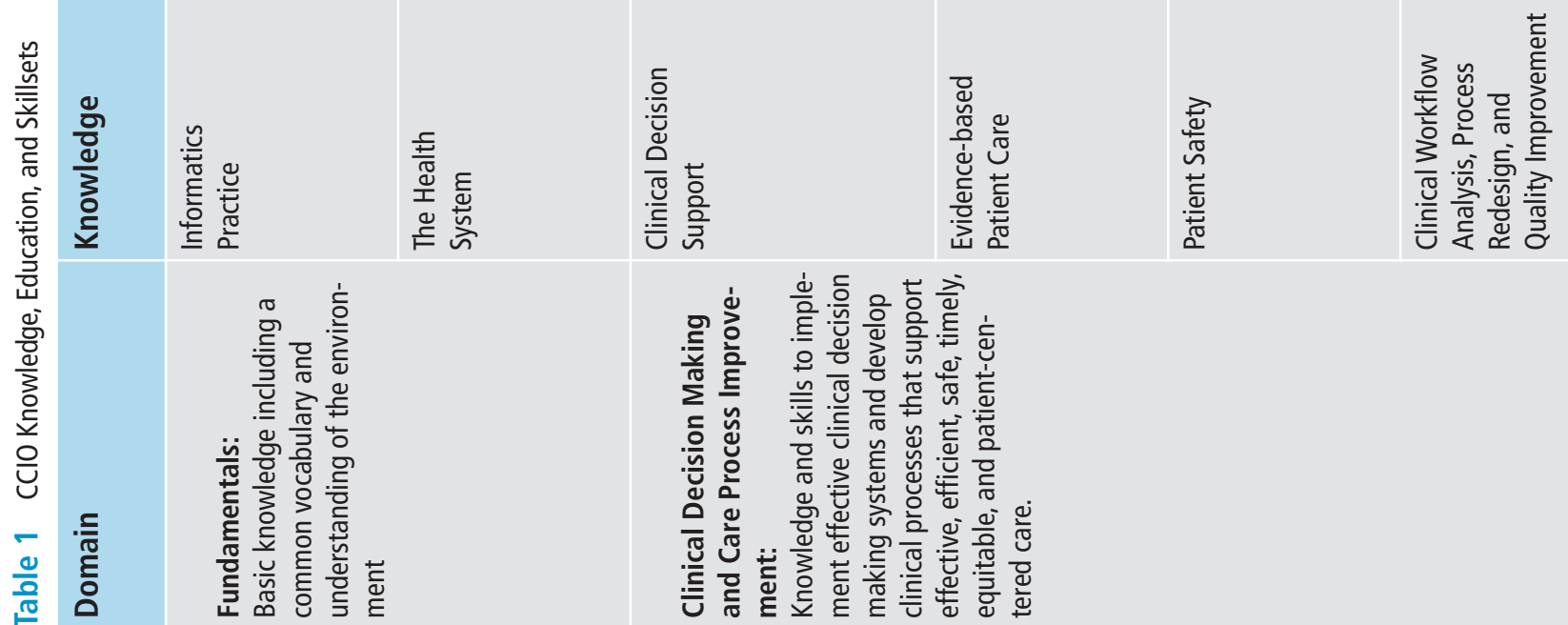


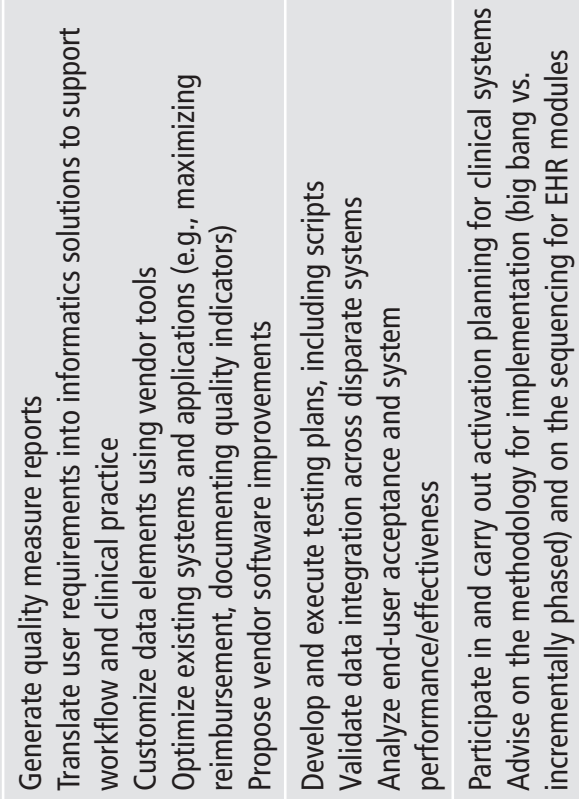

豙

$\overline{0} \frac{\tilde{x}}{x}$

ธ

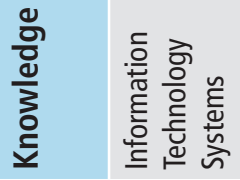

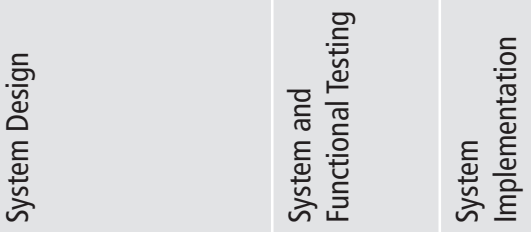

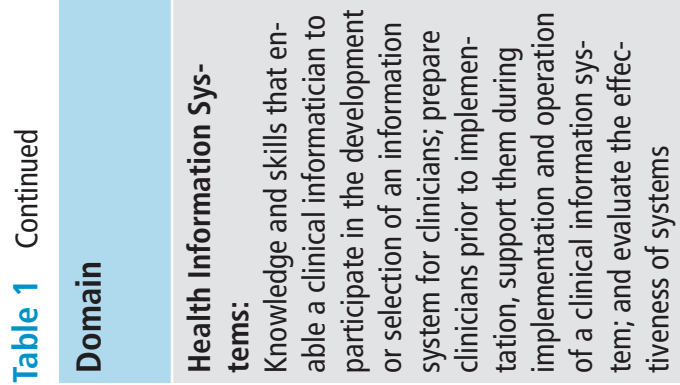




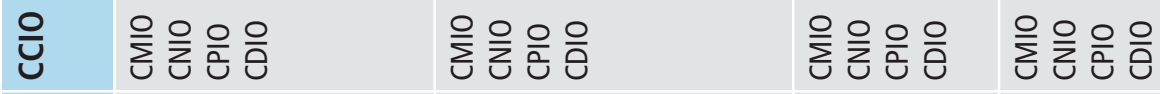

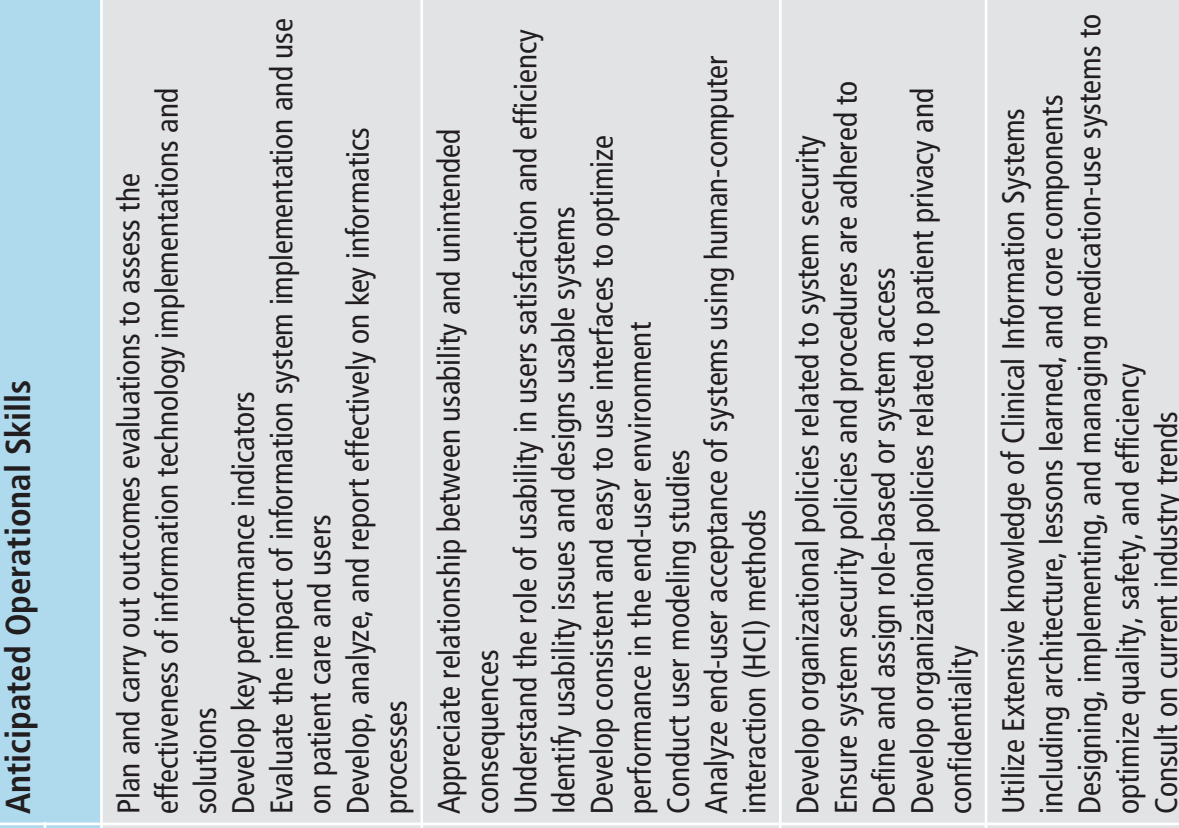
交
$\bar{\emptyset}$

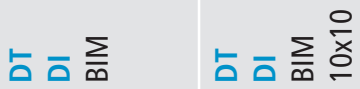
政

วิ

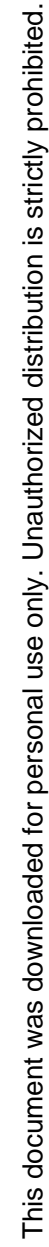
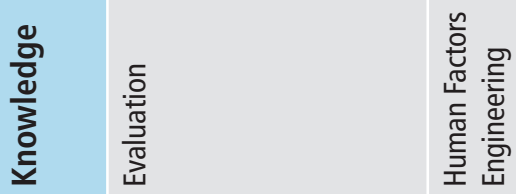

$\overline{\text { a }}$

동 음

它

$\bar{\Sigma} \sum \sum$

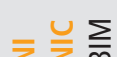

$\bar{\sum} \sum \sum \frac{0}{\bar{x}}$

莺

ভ

ஏ

产. 밓

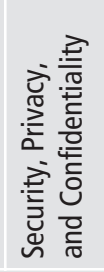
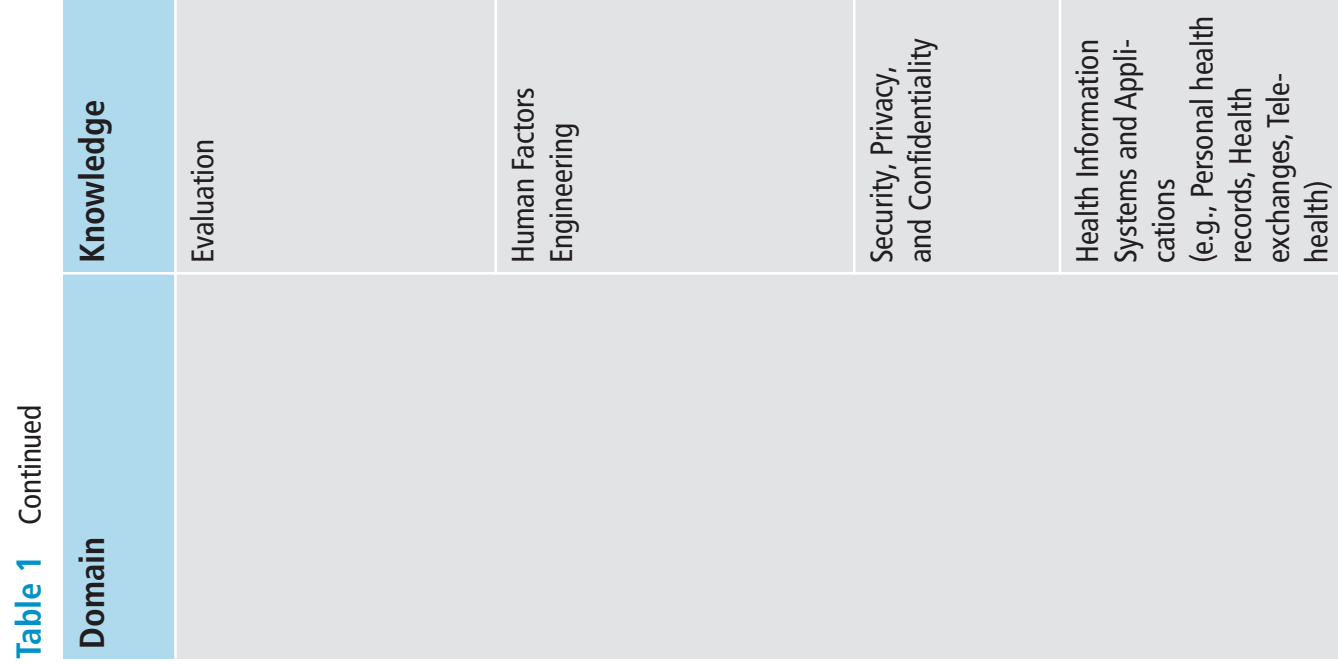
은 올을윤을 을울은을

을을은응 올 을윤을

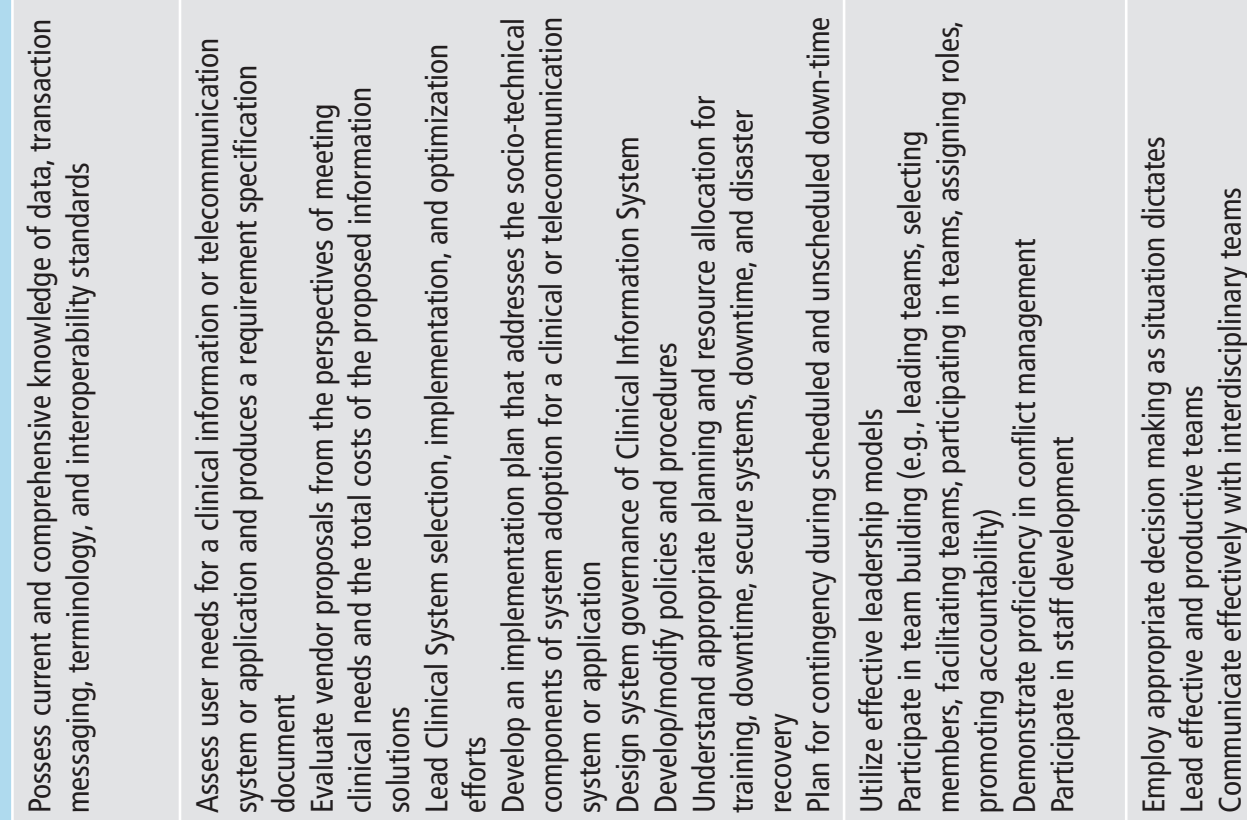

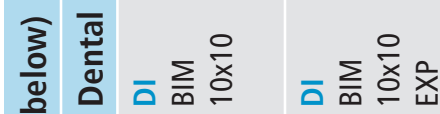

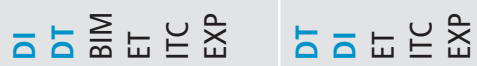

t。

ㅎำ

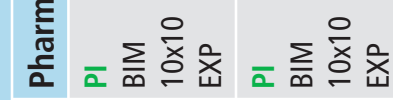

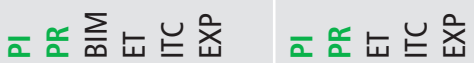

인

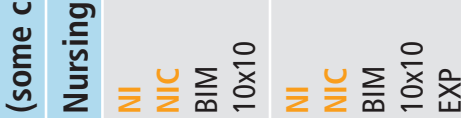

$\sum \overline{\frac{0}{2}} \sum$

흘

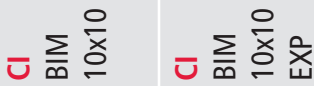

ஏ
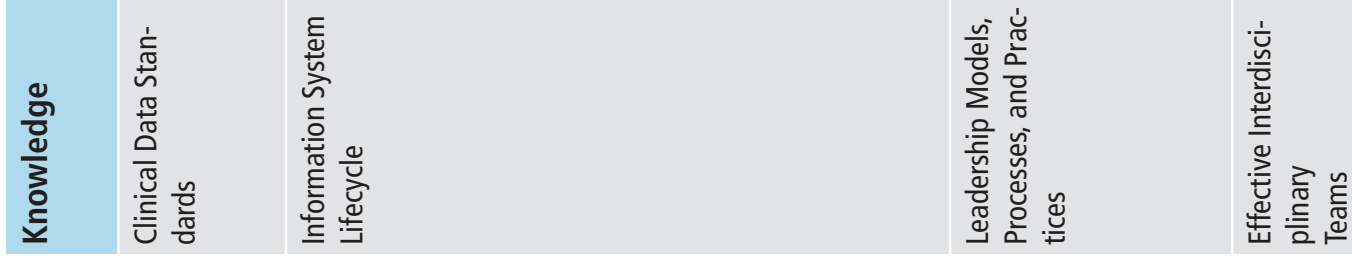



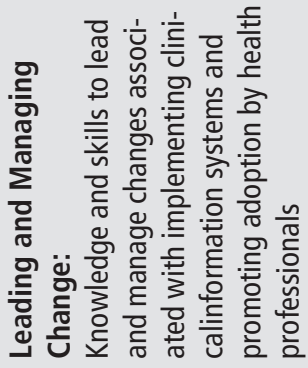




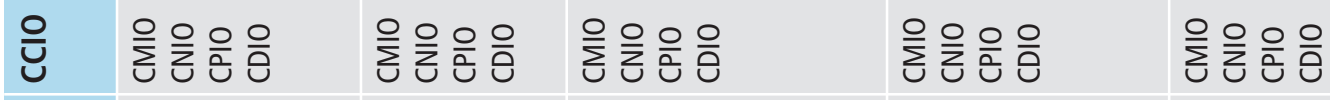
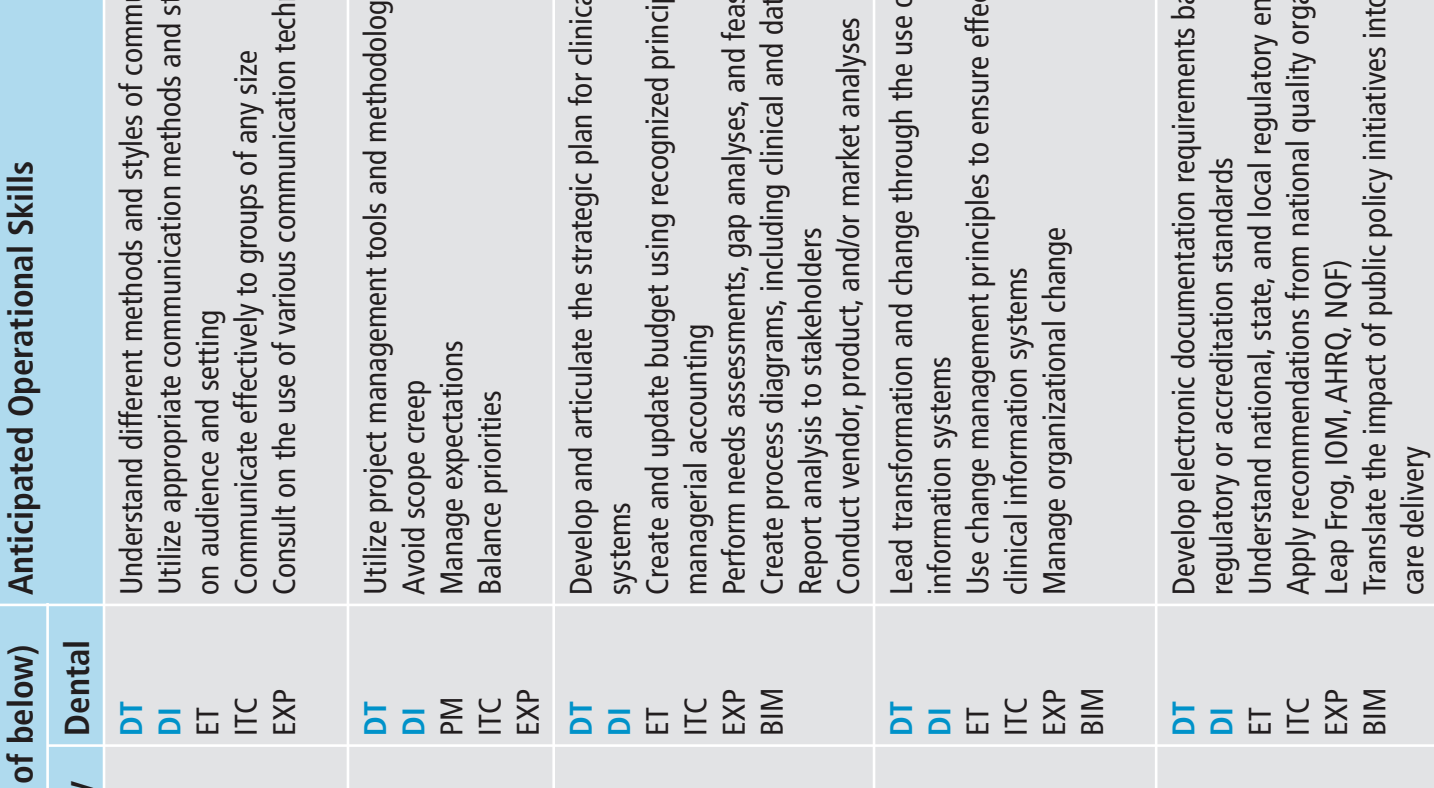

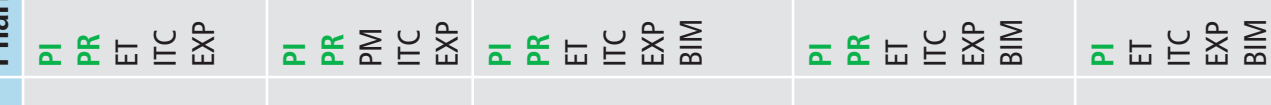

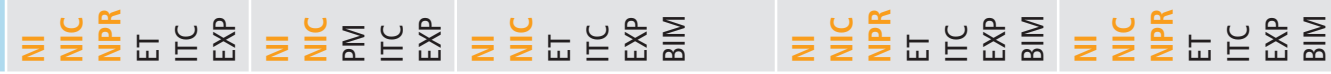

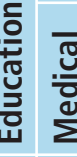

$\bar{\amalg} \longleftarrow$
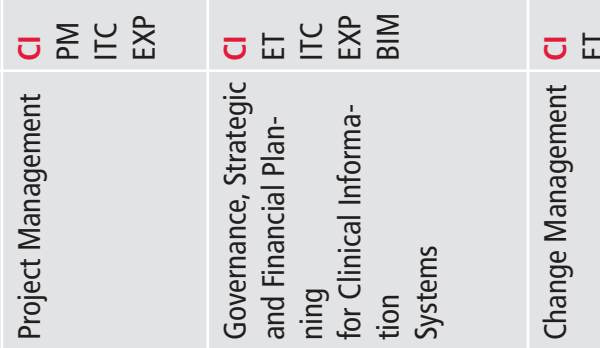

テษヒ妾市
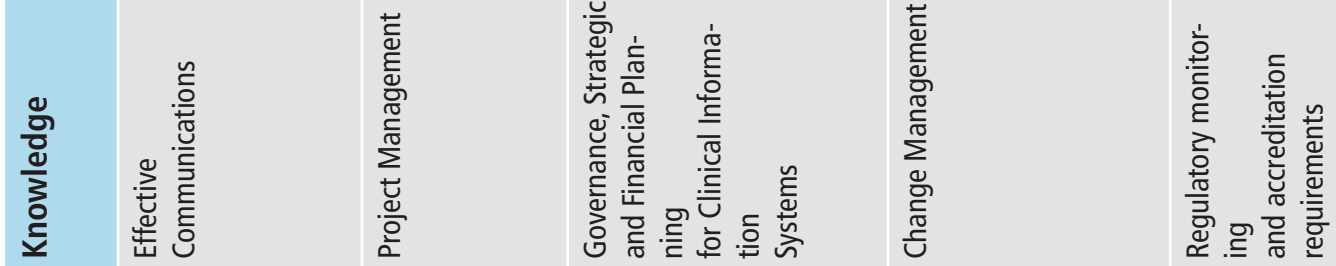

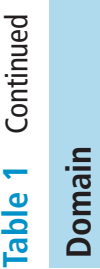


웝 을을은을 을을은은

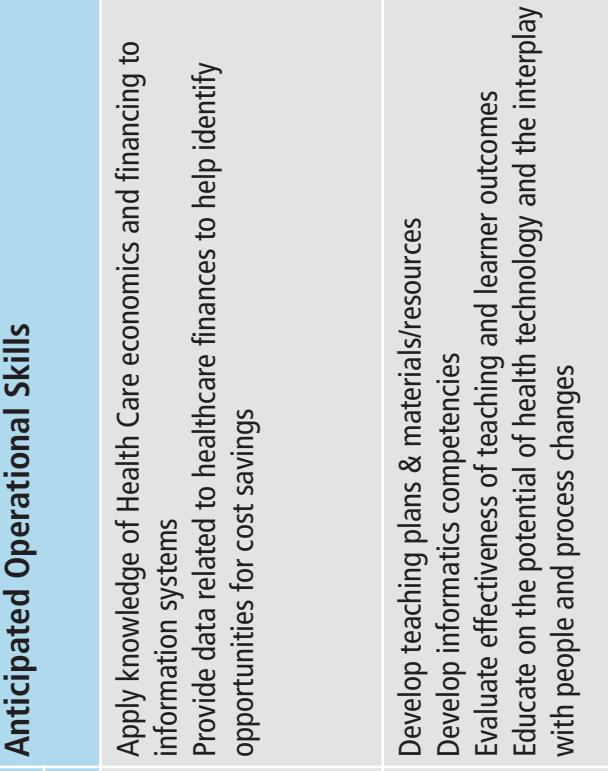

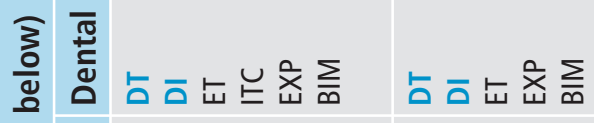
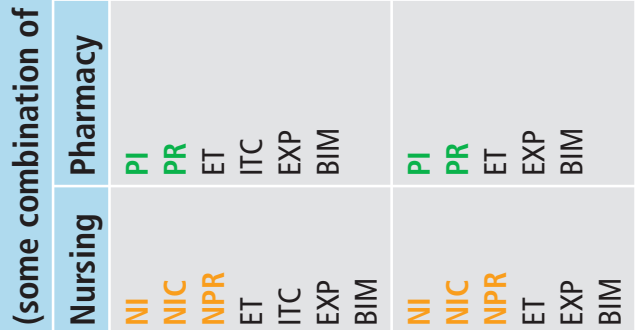

흔

ত্তু

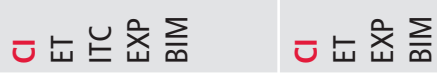
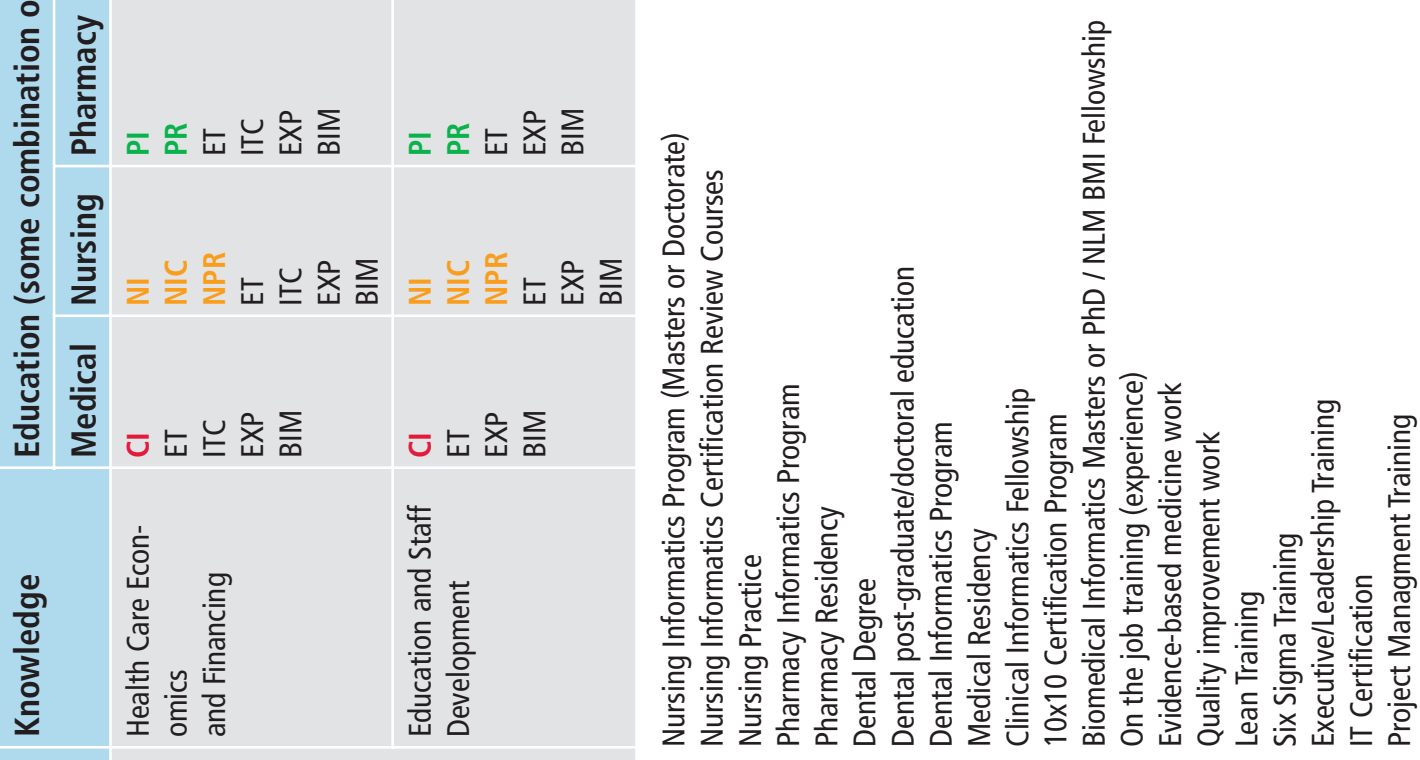

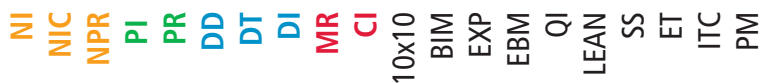

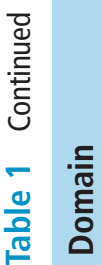




\section{References}

1. ML G, HA. S. Selected Automated Ambulatory Medical Records Systems. In Automated Data Sources for Ambulatory Care Effectiveness Research: Agency For Health Policy and Research1993 Contract No.: Dec 22.

2. The MITRE Corporation. Electronic Health Records Overview. National Institutes of Health National Center for Research Resources.; 2006 [cited 2014 12/21/2014]; Available from: http://www.himss.org/ files/HIMSSorg/content/files/Code\%20180\%20MITRE\%20Key\%20Components\%20of\%20an\%20EHR.pdf.

3. Collen MF. A history of medical informatics in the United States, 1950 to 1990. Indianapolis, IN: American Medical Informatics Association; 1995.

4. Glaser JP, Williams RB. The definitive Evolution of the role of the CIO. J Healthc Inf Manag 2007; 21(1): 9-11.

5. Board A. Pesonal Communication ed2015.

6. Poon, Eric. Pesonal Communication ed2015.

7. Chief medical informatics officer. Wikipedia; [cited 2014 Dec. 21]; Available from: http://en.wikipedia.org/wiki/Chief_medical_informatics_officer.

8. AMIA. Clinical Informatics Board Review Course-History. AMIA; 2014 [cited 2014 June 30, 2014]; Available from: http://www.amia.org/clinical-informatics-board-review-course/history.

9. Kim GR, Lehmann CU. In search of dialogue and discourse in applied clinical informatics. Appl Clin Inform 2009; 0(1): 1-7.

10. Congress OHE. American Recovery and Reinvestment Act of 2009. Washington, DC: GPO; 2009 [cited 2014 June 30]; Available from: http://www.gpo.gov/fdsys/pkg/BILLS-111hrlenr/pdf/BILLS-111hr1enr. pdf.

11. Detmer DE, Lumpkin JR, Williamson JJ. Defining the medical subspecialty of clinical informatics. J Am Med Inform Assoc 2009; 16(2): 167-168.

12. Gardner RM, Overhage JM, Steen EB, Munger BS, Holmes JH, Williamson JJ, Detmer DE. Core content for the subspecialty of clinical informatics. J Am Med Inform Assoc 2009;16(2): 153-157.

13. Safran C, Shabot MM, Munger BS, Holmes JH, Steen EB, Lumpkin JR, Detmer DE. Program requirements for fellowship education in the subspecialty of clinical informatics. J Am Med Inform Assoc 2009;16(2): 158-166.

14. McBride SG, Tietze M, Fenton MV. Developing an applied informatics course for a doctor of nursing practice program. Nurse Educ 2013; 38(1): 37-42.

15. (ANCC) ANCC. Informatics Nursing Board Certification Test Content Outline - effective date: May 7 , 2012. 2012 [cited 2014 July 1, 2014]; Available from: http://www.nursecredentialing.org/Documents/Cer tification/TestContentOutlines/Informatics-TCO2012.aspx.

16. American Nurses Association. Nursing informatics : scope and standards of practice. 2nd ed. Silver Spring, Md.: American Nurses Association; 2015.

17. Technology-enabled practice: a vision statement by the ASHP Section of Pharmacy Informatics and Technology. Am J Health Syst Pharm 2009;66(17): 1573-1577.

18. Fox BI, Flynn AJ, Fortier CR, Clauson KA. Knowledge, skills, and resources for pharmacy informatics education. Am J Pharm Educ 2011; 75(5): 93.

19. Seaton T. Setting the stage: Consensus-based development of pharmacy informatics competencies. Building core competencies in pharmacy informatics Washington, DC: American Pharmacists Association. 2010.

20. Zimmerman JL, Ball MJ, Petroski SP. Computers in dentistry. Dental clinics of North America. 1986; 30(4): 739-743.

21. Schleyer TK, Thyvalikakath TP, Spallek H, Dziabiak MP, Johnson LA. From information technology to informatics: the information revolution in dental education. J Dent Educ 2012; 76(1): 142-153.

22. Dixon P. What's on the CIO's Mind? CIO Connection. 2012(September 21, 2012): 14-15.

23. Ash JS, Fournier L, Stavri PZ, Dykstra R. Principles for a successful computerized physician order entry implementation. AMIA Annu Symp Proc. United States2003. p. 36-40.

24. Craven CK, Sievert MC, Hicks LL, Alexander GL, Hearne LB, Holmes JH. CAH to CAH: EHR implementation advice to critical access hospitals from peer experts and other key informants. Appl Clin Inform 2014; 5(1): 92-117.

25. Ingebrigtsen T, Georgiou A, Clay-Williams R, Magrabi F, Hordern A, Prgomet M, Li J, Westbrook J, Braithwaite J. The impact of clinical leadership on health information technology adoption: Systematic review. Int J Med Inform 2014; 83(6): 393-405. 
26. Kannry J. Computerized Physician Order Entry and Patient Safety: Panacea or Pandora’s Box? . In: Ong KR, editor. Medical informatics : an executive primer. Chicago, IL: HIMSS; 2007. p. xviii, 316 p.

27. Silow-Carroll S, Edwards JN, Rodin D. Using electronic health records to improve quality and efficiency: the experiences of leading hospitals. Issue Brief (Commonw Fund). 2012; 17: 1-40.

28. Bleich HL, Beckley RF, Horowitz GL, Jackson JD, Moody ES, Franklin C, Goodman SR, McKay MW, Pope RA, Walden T, et al. Clinical computing in a teaching hospital. N Engl J Med 1985; 312(12): 756-764.

29. Garibaldi RA. Computers and the quality of care - a clinician's perspective. N Engl J Med 1998; 338(4): 259-260.

30. McDonald CJ, Hui SL, Smith DM, Tierney WM, Cohen SJ, Weinberger M, McCabe GP. Reminders to physicians from an introspective computer medical record. A two-year randomized trial. Ann Intern Med 1984; 100(1): 130-138.

31. Tierney WM, McDonald CJ, Martin DK, Rogers MP. Computerized display of past test results. Effect on outpatient testing. Ann Intern Med 1987; 107(4): 569-574.

32. Miller RA, Pople HE, Jr., Myers JD. Internist-1, an experimental computer-based diagnostic consultant for general internal medicine. N Engl J Med 1982; 307(8): 468-476.

33. Friedman BA. The potential role of physicians in the management of hospital information systems. Clin Lab Med 1990; 10(1): 239-250.

34. Friedman BA, Martin JB. The physician as a locus of authority, responsibility, and operational control of medical systems. J Med Syst 1988; 12(6): 389-396.

35. Frisse ME, Musen MA, Slack WV, Stead WW. How should we organize to do informatics? Report of the ACMI Debate at the 1997 AMIA Fall Symposium. Journal of the American Medical Informatics Association 1998; 5(3): 293-304.

36. Slack WV, Bleich HL. The CCC system in two teaching hospitals: a progress report. International Journal of Medical Informatics 1999; 54(3): 183-196.

37. Kannry J. Pesonal Communication ed2014.

38. Barnett GO. The application of computer-based medical-record systems in ambulatory practice. $\mathrm{N}$ Engl J Med 1984; 310(25): 1643-1650.

39. Pryor TA, Gardner RM, Clayton PD, Warner HR. The HELP system. J Med Syst 1983; 7(2): 87-102.

40. Gardner RM, Pryor TA, Warner HR. The HELP hospital information system: update 1998. Int J Med Inf 1999; 54(3): 169-182.

41. Halamka JD, Osterland C, Safran C. CareWeb, a web-based medical record for an integrated health care delivery system. International journal of medical informatics 1999; 54(1): 1-8.

42. McDonald CJ, Overhage JM, Tierney WM, Dexter PR, Martin DK, Suico JG, Zafar A, Schadow G, Blevins L, Glazener T, Meeks-Johnson J, Lemmon L, Warvel J, Porterfield B, Cassidy P, Lindbergh D, Belsito A, Tucker M, Williams B, Wodniak C. The Regenstrief Medical Record System: a quarter century experience. International journal of medical informatics 1999; 54(3): 225-253.

43. Safran C, Sands DZ, Rind DM. Online medical records: a decade of experience. Methods of information in medicine. 1999; 38(4-5): 308-312.

44. Slack WV, Bleich HL. The CCC system in two teaching hospitals: a progress report. Int J Med Inf 1999; 54(3): 183-196.

45. Teich JM, Glaser JP, Beckley RF, Aranow M, Bates DW, Kuperman GJ, Ward ME, Spurr CD. The Brigham integrated computing system (BICS): advanced clinical systems in an academic hospital environment. Int J Med Inf 1999; 54(3): 197-208.

46. Morgan MW. The VA advantage: the gold standard in clinical informatics. Healthc Pap 2005; 5(4): 26-29.

47. Miller RA, Waitman LR, Chen S, Rosenbloom ST. The anatomy of decision support during inpatient care provider order entry (CPOE): empirical observations from a decade of CPOE experience at Vanderbilt. Journal of biomedical informatics. 2005; 38(6): 469-485.

48. Davies NE. The National Library of Medicine and the American medical information system: the physician's perspective. Bull Med Libr Assoc 1986; 74(4): 333-338.

49. Aronow DB, Payne TH, Pincetl SP. Postdoctoral training in medical informatics: a survey of National Library of Medicine-supported fellows. Med Decis Making 1991; 11(1): 29-32.

50. Hersher B. The essential skills for the chief medical information officer. J Healthc Inf Manag 2003; 17(1): 10-11.

51. Kannry J, Glaser J, Hersher B, Karson T, editors. The Making of a Clinical Informaticist: Factors for Success in the Enterprise. 2001 American Medical Informatics Association Annual Fall Symposium, 2001; Washington, DC.: Hanley Belfus, Inc. 
52. Karson T, Kannry J, Glaser J, Hersher B, Tintzman T, editors. The Role of Clinical Informatics in the Enterprise. 2001 Annual Health Information Management Systems Society Conference; 2001; New Orlean, La.: HIMSS.

53. Ash JS, Sittig DF, Seshadri V, Dykstra RH, Carpenter JD, Stavri PZ. Adding insight: A qualitative crosssite study of physician order entry. International Journal of Medical Informatics 2005; 74(7-8): 623-628.

54. Ash JS, Stavri PZ, Dykstra R, Fournier L. Implementing computerized physician order entry: the importance of special people. International Journal of Medical Informatics 2003; 69(2-3): 235-250.

55. CHIMES. Despite Trend Toward Increasing Influence of CMIOs, CHIME Survey Shows Little Growth in Numbers. College of Health Information Executives (CHIMES); 2007 [cited 2011 April 25]; Available from: http://www.cio-chime.org/chime/pressreleases/pr6_1_2007_12_34_52.asp.

56. CMIO.NET. CMIO-CHIME IT Leadership Survey. Trimed Media Group; 2011 [cited 2014 June 13, 2014]; Available from: http://www.slideshare.net/alizotte/cmio-chime-survey-re sults?qid=48397e1d-81eb-4201-9851-506ef5c02064\&v=default\&b=\&from_search=1.

57. Walsh B. CMIO 2012 Compensation Survey: Small Salary Shifts and Less Satisfaction. CMIO Magazine; 2012 [cited 2014 March 4]; Available from: http://www.clinical-innovation.com/topics/technology-man agement/cmio-2012-compensation-survey-small-salary-shifts-and-less-satisfaction?page $=0 \% 2 \mathrm{C} 1$.

58. CMS. EHR Incentive Program: Data and Reports-August 2015. 2015 [updated August 2015; cited 2015 October 1]; Available from: https://www.cms.gov/Regulations-and-Guidance/Legislation/EHRIncentive Programs/Downloads/August2015_SummaryReport.pdf.

59. Jeff Williamson AED.

60. Detmer DE, Munger BS, Lehmann CU. Clinical informatics board certification: history, current status, and predicted impact on the clinical informatics workforce. Appl Clin Inform 2010; 1(1): 11-18.

61. Ozbolt JG, Saba VK. A brief history of nursing informatics in the United States of America. Nurs Outlook 2008; 56(5): 199-205 e2.

62. AONE. AONE(2012): Position Paper: Nursing Informatics Executive Leader. 2012.

63. Harrington L, CPHIMS F. AONE Creates New Position Paper: Nursing Informatics Executive Leader. Nurse Leader. 2012; 10(3): 17-18.

64. Telephony: The American Telphone Journal 1913; 65: 30.

65. Hall EJ. Hermes Drug in La Grange: a Pioneer Texas Store. The Southwestern historical quarterly 1966: 65-70.

66. Hansten P. Retrieval and utilization of drug interaction information. American Journal of Health-System Pharmacy 1970; 27(6): 468-472.

67. Poikonen J. Pesonal Communication ed2014.

68. Schleyer T, Song M, Gilbert GH, Rindal DB, Fellows JL, Gordan VV, Funkhouser E. Electronic dental record use and clinical information management patterns among practitioner-investigators in The Dental Practice-Based Research Network. J Am Dent Assoc 2013; 144(1): 49-58.

69. Schleyer TK, Thyvalikakath TP, Spallek H, Torres-Urquidy MH, Hernandez P, Yuhaniak J. Clinical computing in general dentistry. J Am Med Inform Assoc 2006; 13(3): 344-352.

70. WHO (World Health Organization). Oral Health: What is the Burden? 2014 [cited 2014 July 1, 2014]; Available from: http://www.who.int/oral_health/disease_burden/global/en/.

71. Hill HK, Stewart DC, Ash JS. Health Information Technology Systems profoundly impact users: a case study in a dental school. J Dent Educ 2010; 74(4): 434-445.

72. Thyvalikakath TP, Monaco V, Thambuganipalle HB, Schleyer T. A usability evaluation of four commercial dental computer-based patient record systems. J Am Dent Assoc 2008; 139(12): 1632-1642.

73. Walji MF, Taylor D, Langabeer JR, 2nd, Valenza JA. Factors influencing implementation and outcomes of a dental electronic patient record system. J Dent Educ 2009; 73(5): 589-600.

74. Song M, Liu K, Abromitis R, Schleyer TL. Reusing electronic patient data for dental clinical research: a review of current status. Journal of dentistry 2013; 41(12): 1148-1163.

75. Leviss J, Kremsdorf R, Mohaideen MF. The CMIO - a new leader for health systems. J Am Med Inform Assoc. United States 2006. 573-578.

76. Hagland M. CMIOs roaring ahead: a new survey released at the AMDIS Symposium charts the growth of CMIOs' stature in their organizations. Healthcare Informatics via The Free Library.; 2011 [updated October 1, 2011; cited 2014 June 13, 2014]; Available from: http://www.thefreelibrary.com/CMIOs+roar ing+ahead\%3a+a+new+survey+released+at+the+AMDIS+Symposium...-a0270531562.

77. Hersh W. The health information technology workforce: estimations of demands and a framework for requirements. Applied clinical informatics 2010; 1(2): 197.

78. Poe SS. The Chief Nursing Information Officers Impact on Electronic Health Record Implementation. iHealth Connections 2011; 1(1): 61-63. 
79. Committee on the Robert Wood Johnson Foundation Initiative on the Future of Nursing at the Institute of Medicine., Robert Wood Johnson Foundation., Institute of Medicine (U.S.). The future of nursing : leading change, advancing health. Washington, D.C.: National Academies Press; 2011.

80. HIMSS position statement on transforming nursing practice through technology \& informatics: (approved by the HIMSS Board of Directors June 17, 2011). Crit Care Nurs Q 2011; 34(4): 367-376.

81. Sensmeier J. Transforming nursing practice through technology and informatics. Nursing management 2011; 42(11): 20-23.

82. Murphy J. The nursing informatics workforce: who are they and what do they do? Nurs Econ 2011; 29(3): 150-153.

83. Davis C, Stoots M. A guide to EHR adoption : implementation through organizational transformation. Chicago, IL.: HIMSS (Healthcare Information and Management Systems Society); 2012.

84. Hodges L, Wierz C, editors. The Emerging Role of the Chief Nursing Information Officer: What is the Current State? HIMSS Symposium 2012; 2012: HIMSS.

85. American Society of Health-System Pharmacists. ASHP statement on the pharmacist's role in informatics. Am J Health-Syst Pharm 2007; 64(2): 200-203.

86. Rough S, Shane R, Phelps P, Klauck J, Donnelly AJ, Besier JL, Cotugno M, Martin P, Cheng Y, Sherman KC. A solution to an unmet need: Pharmacy specialists in medication-use systems and technology Am J Health Syst Pharm October.

87. Johnston D, Pan E, Walker J, Bates DW, Middleton B. The Value of Computerized Provider Order Entry in Ambulatory Settings. Botson: Center for Information Technology Leadership (CITL) 2003.

88. Johnston D, Pan E, Walker J, Bates DW, Middleton B. Patient Safety in the Physician's Office: Assessing the Value of Ambulatory CPOE2004: Available from: http://www.chcf.org/ /media/Files/PDF/ P/PDF\%20PatientSafetyInPhysiciansOfficeACPOE.pdf.

89. Accreditation Council For Pharmacy Education. Accreditation Standards and Gudielines For The Professional Program in Pharmacy Leading To The Doctor Of Pharmacy Degree. 2014 [cited 2014 July 1, 2014]; Available from: https://www.acpe-accredit.org/pdf/S2007Guidelines2.0_ChangesIdentifiedInRed. pdf.

90. American Medical Informatics Association. Advanced Interprofessional Informatics Certification (AIIC) Program. 2014 [cited 2015 Jan. 20]; Available from: http://www.amia.org/advanced-interprofessional-in formatics-certification.

91. Nattestad A. Knowledge management systems for oral health in developing and developed countries. Periodontol 2000 2012; 60(1): 156-161.

92. Thyvalikakath TP. Designing clinical data presentation using cognitive task analysis methods. Pittsburgh, PA: University of Pittsburgh; 2012.

93. Loeb P, McGibony R, Yeung P. Health Information Technology in California Dental Practices: Survey Findings. CHCF; 2010.

94. American Dental Association Survey Center. 2006 Technology Survey. Chicago2007.

95. Medicare and Medicaid programs; electronic health record incentive program. Final rule. Fed Regist 2010; 75(144): 44313-44588.

96. Thyvalikakath TP. Pesonal Communication ed2014.

97. Field MJ. Dental education at the crossroads: National Academy Press; 1995.

98. Douglass CW. Risk assessment and management of periodontal disease. J Am Dent Assoc 2006; 137(Suppl.): 27S-32S.

99. Page RC, Krall EA, Martin J, Mancl L, Garcia RI. Validity and accuracy of a risk calculator in predicting periodontal disease. J Am Dent Assoc 2002; 133(5): 569-576.

100. Samal L, Stavroudis T, Miller R, Lehmann H, Lehmann C. Effect of a laboratory result pager on provider behavior in a neonatal intensive care unit. Appl Clin Inform 2011; 2(3): 384-394.

101. Harrison MI, Koppel R, Bar-Lev S. Unintended consequences of information technologies in health care--an interactive sociotechnical analysis. J Am Med Inform Assoc 2007; 14(5): 542-549.

102. Koppel R, Metlay JP, Cohen A, Abaluck B, Localio AR, Kimmel SE, Strom BL. Role of computerized physician order entry systems in facilitating medication errors. Jama 2005; 293(10): 1197-1203.

103. Han YY, Carcillo JA, Venkataraman ST, Clark RS, Watson RS, Nguyen TC, Bayir H, Orr RA. Unexpected increased mortality after implementation of a commercially sold computerized physician order entry system. Pediatrics 2005; 116(6): 1506-1512.

104. Kannry J. Computerized Physician Order Entry and Patient Safety: Panacea or Pandora’s Box? . In: Ong K, editor. Medical Informatics: An Executive Primer. Chicago: HIMSS; 2007.

105. Kim GR, Miller MR, Ardolino MA, Smith JE, Lee DC, Lehmann CU. Capture and classification of problems during CPOE deployment in an academic pediatric center. AMIA Annu Symp Proc 2007: 414-417. 
106.Knebel E, Greiner AC. Health Professions Education:: A Bridge to Quality: National Academies Press; 2003.

107. Tribble DA, Poikonen J, Blair J, Briley DC. Whither pharmacy informatics. Am J Health Syst Pharm 2009; 66(9): 813-815.

108. ACGME. ACGME Program Requirements for Graduate Medical Education in Clinical Informatics (Review Committees for Anesthesiology, Diagnostic Radiology, Emergency Medicine, Family Medicine, Internal Medicine, Medical Genetics, Pathology, Pediatrics, or Preventive Medicine) 2014.

109. American Society of Health-System Pharmacists. Educational Outcomes, Goals, and Objectives for Postgraduate Year Two (PGY2) Pharmacy Informatics Residency Programs.

110. Kalenderian E, Walji M, Ramoni RB. „Meaningful use“ of EHR in dental school clinics: how to benefit from the U.S. HITECH Act's financial and quality improvement incentives. J Dent Educ 2013; 77(4): 401-415.

111. Bates DW, Kuperman GJ, Wang S, Gandhi T, Kittler A, Volk L, Spurr C, Khorasani R, Tanasijevic M, Middleton B. Ten commandments for effective clinical decision support: making the practice of evidence-based medicine a reality. Journal of the American Medical Informatics Association : JAMIA 2003; 10(6): 523-530.

112.Dixon P. The Current State of the Evolving CIO-CMIO Relationship. HealthCare Informatics 2012 (October 10, 2012). 